\title{
Ion Beam Analysis of fusion plasma-facing materials and components: Facilities and Research Challenges
}

\author{
M. Mayer ${ }^{1^{*}}$, S. Möller ${ }^{2}$, M. Rubel ${ }^{3}$, A. Widdowson ${ }^{4}$, S. Charisopoulos ${ }^{5}$, T. Ahlgren ${ }^{6}$, \\ E. Alves ${ }^{7}$, G. Apostolopoulos ${ }^{8}$, N.P. Barradas ${ }^{5}$, S. Donnelly ${ }^{9}$, S. Fazinic ${ }^{10}$, K. Heinola ${ }^{5}$, \\ O. Kakuee ${ }^{11}$, H. Khodja ${ }^{12}$, A. Kimura ${ }^{13}$, A. Lagoyannis ${ }^{14}$, M. Li $^{15}$, S. Markelj ${ }^{16}$, M. \\ Mudrinic $^{17}$, P. Petersson ${ }^{3}$, I. Portnykh ${ }^{18}$, D. Primetzhofer ${ }^{19}$, P. Reichart ${ }^{20}$, D. \\ Ridikas $^{5}$, T. Silva ${ }^{21}$, S. M. Gonzalez de Vicente ${ }^{5}$, and Y.Q. Wang ${ }^{22}$ \\ ${ }^{1}$ Max-Planck-Institut für Plasmaphysik, 85748 Garching, Germany \\ ${ }^{2}$ Institut für Klima- und Energieforschung, Forschungszentrum Jülich, 52425 Jülich, Germany \\ ${ }^{3}$ Fusion Plasma Physics, KTH Royal Institute of Technology, 10044 Stockholm, Sweden \\ ${ }^{4}$ Culham Centre for Fusion Energy, Culham Science Centre, Abingdon, OX14 3DB, UK \\ ${ }^{5}$ International Atomic Energy Agency, Vienna International Centre, PO Box 100, 1400 Vienna, Austria \\ ${ }^{6}$ University of Helsinki, 00014 Helsinki, Finland \\ ${ }^{7}$ Instituto Superior Técnico, Universidade de Lisboa, 1049-001 Lisbon, Portugal \\ ${ }^{8}$ INRASTES, NCSR "Demokritos", 15310 Aghia Paraskevi, Athens, Greece \\ ${ }^{9}$ University of Huddersfield, Ion Beam Centre, Queensgate, Huddersfield HD1 3DH, UK \\ ${ }^{10}$ Ruđer Bošković Institute, Bijenička 54, 10000 Zagreb, Croatia \\ ${ }^{11}$ Nuclear Science and Technology Research Institute, P O Box 14395-836, Tehran, Iran \\ ${ }^{12}$ LEEL, NIMBE, CEA, CNRS, Université Paris-Saclay, CEA Saclay, 91191 Gif sur Yvette Cedex, \\ France \\ ${ }^{13}$ Kyoto University, Institute of Advanced Energy, Gokasho, Uji, 611-0011 Kyoto-Fu, Japan \\ ${ }^{14}$ Tandem Accelerator Laboratory, Institute of Nuclear and Particle Physics, NCSR "Demokritos", \\ 15310 Aghia Paraskevi, Athens, Greece \\ ${ }^{15}$ Argonne National Laboratory, 9700 Cass Avenue, Lemont, Illinois 60439, USA \\ ${ }^{16}$ Jožef Stefan Institute, Jamova cesta 39, 1000 Ljubljana, Slovenia \\ ${ }^{17}$ Vinca Institute of Nuclear Sciences, Belgrade, Serbia \\ ${ }^{18}$ Joint Stock Company Inst. of Nuclear Materials, Box 29, Zarechny, Sverdlovsk region, 624250 Russia \\ ${ }^{19}$ Department of Physics and Astronomy, Uppsala University, Box 516, 75120 Uppsala, Sweden \\ ${ }^{20}$ Universität der Bundeswehr München, 85579 Neubiberg, Germany \\ ${ }^{21}$ Institute of Physics, University of São Paulo, CEP 05508-090 Cidade Universitária, São Paulo, Brasil \\ ${ }^{22}$ Los Alamos National Laboratory, Los Alamos, New Mexico 87545, USA
}

E-mail: matej.mayer@ipp.mpg.de

Received 28 March 2019, revised 4 November 2019

Accepted for publication 15 November 2019

Published 13 December 2019

\section{Abstract}

Following the IAEA Technical Meeting on "Advanced Methodologies for the Analysis of Materials in Energy Applications Using Ion Beam Accelerators", this paper reviews the current status of ion beam analysis techniques and some aspects of ion-induced radiation damage in materials for the field of materials relevant to fusion. Available facilities, apparatus development and future research options and challenges are presented and discussed. The analysis of beryllium and radioactivity-containing samples from future experiments in JET or ITER represents not only an analytical but also a technical challenge. A comprehensive list of the facilities, their current status, and analytical capabilities comes alongside detailed descriptions of the labs. A discussion of future issues of sample handling and the current status of facilities at JET complete the technical section. 
To prepare the international ion beam analysis community for these challenges, the IAEA technical meeting concludes the necessity for determining new nuclear reaction cross-sections and improving the inter-laboratory comparability by defining international standards and testing these via a round-robin test.

Keywords: Ion beam analysis, nuclear reaction, controlled fusion, first wall materials, beryllium, deuterium

\begin{tabular}{llll}
\hline List of Acronyms of Analysis Methods & & \\
AES & Auger Electron Spectroscopy & NRA & Nuclear Reaction Analysis \\
AFM & Atomic Force Microscopy & PALS & Positron Annihilation Lifetime Spectroscopy \\
EBS & (non-Rutherford) Elastic Backscattering Spectrometry & PAS & Positron Annihilation Spectroscopy \\
EDX & Energy Dispersive X-ray spectroscopy & PFC & Plasma-Facing Component \\
EPMA & Electron Probe Micro-Analysis & PIGE & Particle Induced Gamma Emission \\
ERDA & Elastic Recoil Detection Analysis & PIXE & Particle Induced X-ray Emission \\
HI-ERDA & Heavy Ion ERDA & PWI & Plasma-Wall Interactions \\
IBA & Ion Beam Analysis & RBS & Rutherford Backscattering Spectrometry \\
IBAD & Ion Beam Assisted (thin film) Deposition & SEM & Scanning Electron Microscopy \\
IBANDL & IBA Nuclear Data Library & SIMS & Secondary Ion Mass Spectrometry \\
IBIC & Ion Beam Induced Charge imaging & STIM & Scanning Transmission Ion Microscopy \\
IBIL & Ion Beam Induced Luminescence & STM & Scanning Tunnelling Microscopy \\
LEED & Low Energy Electron Diffraction & STEM & Scanning Transmission Electron Microscopy \\
LEID & Low Energy Ion Deposition & ToF & Time-of-Flight \\
LEIS & Low Energy Ion Scattering & TEM & Transmission Electron Microscopy \\
MEIS & Medium Energy Ion Scattering & UHV & Ultra High Vacuum
\end{tabular}

\section{Introduction}

Plasma-wall interactions (PWI) in controlled fusion devices with magnetic confinement comprise all processes involved in the energy and mass exchange between the plasma and the surrounding materials and components [1-4]. Ions, electrons, charge-exchange neutrals, neutrons and electromagnetic radiation of a broad energy range cause severe modification of the physico-chemical and thermomechanical properties of wall materials and are responsible for erosion of plasma-facing components (PFCs). The main erosion mechanisms are: physical sputtering, chemical erosion, melting and melt layer splashing, evaporation, arcing, photo- and electron-induced desorption. Neutron irradiation changes properties not only of PFCs, but also of structural, functional (e.g. tritium breeders and diagnostics) and other materials affected by the neutron field.

As a consequence, there is need for detailed material analyses and for experimental simulation of radiationinduced damage. In both cases accelerator-based ion beam techniques play prominent roles either in ion beam analysis (IBA) or as tools for fast and efficient creation of radiation damage in solids for simulating certain effects connected with the impact of fast ions and neutrons. In these two interrelated fields of ion beam physics a number of issues have to be evaluated or re-assessed in order to further improve the reliability of data. These facts have motivated and laid grounds for the Technical Meeting on "Advanced Methodologies for the Analysis of Materials in Energy Applications Using Ion Beam Accelerators" organized by the International Atomic Energy Agency (IAEA). The main goal was to review the current status and next steps in the following areas:
- Accelerator laboratories and their research potential for IBA of materials for fusion applications;

- IBA in fusion plasma-facing components and materials, including combinations of different ion beam methods;

- Fundamental aspects of employing ion beams for simulating radiation damage phenomena in materials for fusion energy production;

- Modelling tools and software development with emphasis on the analysis of materials employed in fusion applications;

- A cross-section database for IBA in fusion applications; data availability, exchange and further needs;

- A roadmap for future studies of fusion reactor materials using ion beam accelerators.

This paper provides a critical assessment of the status and further needs in IBA experiments and computer modelling. The aspect of ion induced radiation damage is related to IBA, but will not be covered here. First, main aspects of PWI are briefly introduced followed by a comprehensive overview of research capabilities in accelerator laboratories. Special requirements associated with studies of wall materials from fusion devices are discussed and strong emphasis is given to a holistic approach in handling of contaminated or activated materials from fusion reactors and/or irradiation facilities. Research capabilities comprise also complex computer codes constituting fundamental tools for analysis and interpretation of IBA spectra. Their accuracy depends on the availability of evaluated data for stopping powers and cross-sections over a broad range of projectile energies and system geometries. Examples will be shown to illustrate difficult cases from the analytical point of view. The paper is concluded with a definition of specific tasks towards obtaining improved data sets for several projectile-target combinations and other 
requirements for successful IBA measurements for fusion research.

\section{The role of ion beam analysis for plasma-wall interaction research}

Plasma-facing materials and components are subjected to bombardment by charged and neutral particles escaping the plasma and by electromagnetic radiation related to electronic and nuclear processes. As a consequence, physical, chemical and thermo-mechanical properties of the wall materials are modified by physical sputtering, ion-assisted chemical erosion, implantation, melting, evaporation, arcing and - in the case of neutrons - by transmutation. At the same time the plasma is contaminated by species removed from the wall. Such impurity atoms are ionized when entering the plasma edge and are then transported along the magnetic field lines until they get re-deposited or pumped out. Re-deposition of all types of impurities present in the system together with hydrogen isotopes leads to the formation of co-deposited layers. These processes of erosion, re-deposition (with codeposition) and potentially further re-erosion are responsible for material migration and mixing including the growth of fuel-rich mixed-material layers, i.e. co-deposits. Their detailed composition and structure cannot be foreseen a priori.

The main objective of PWI research is the determination of global changes of the plasma-facing wall in order to predict the lifetime of materials and components, the fuel inventory and the generation of dust by exfoliation of codeposits, melting and splashing (in the case of metals) and brittle destruction (especially of carbon materials) under offnormal events and high local power loads.

The behavior and modification of materials under fusionrelevant conditions is studied in controlled fusion devices and in laboratory systems capable of simulating PWI processes by thorough material analyses before and after exposure to these extreme environments. The key point in analytical work is to achieve an as detailed as possible map of erosion and deposition zones, to determine material modifications, and to determine the influence of wall composition on the overall material migration. This includes the quantification of fuel retention in the bulk of wall materials and in co-deposited layers.

Figure 1 shows the interior of the vacuum vessel of the Joint European Torus (JET), located at the Culham Science Centre, United Kingdom. In figure 1(a) one perceives the great complexity of the plasma-facing wall: various types of limiters in the main chamber (details in the figure caption), protection of the central column (Inner Wall Cladding, IWC) and the divertor channel. Respective groups of PFCs are made of different materials (color-coded in figure $1 \mathrm{~b}$ ) to meet the operation criteria. Limiter tiles are made from bulk beryllium, while the recessed IWC tiles are made of cast
Inconel. The majority of them is coated with evaporated beryllium, but in the upper part of the vessel Inconel is protected by a tungsten layer. Tungsten is used for divertor components either as coatings on carbon fibre composite (CFC) blocks in the outer and inner leg or bulk W lamellae for the outer divertor load bearing tiles. Detailed images of a few types of JET tiles are shown in figure 2. An important feature of all of those items is their size and - in some cases significant weight. Therefore, the technical parameters of surface analysis stations must meet the criteria for handling such components; this point is discussed in Chapter 4.

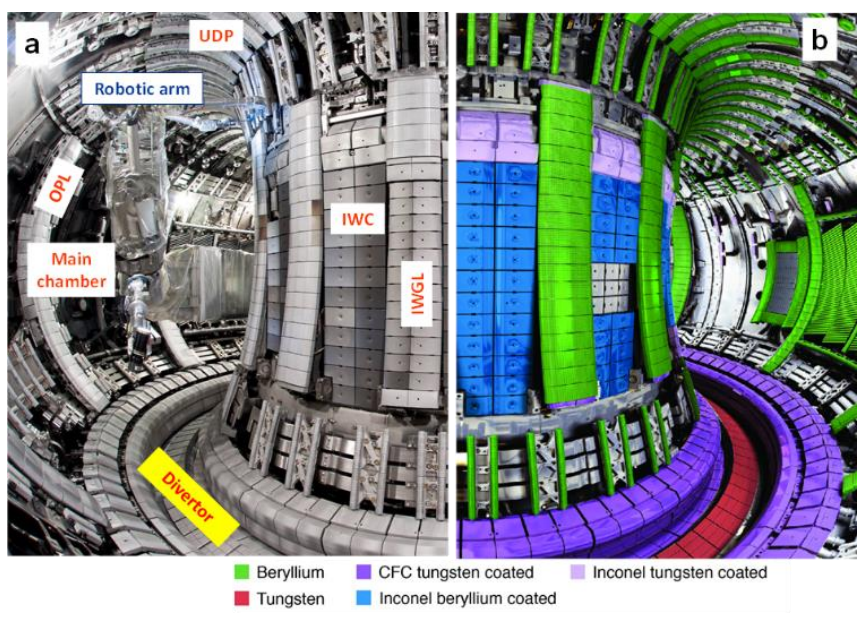

Figure 1. Toroidal view into the JET tokamak with the ITER-like wall (ILW): (a) structure of the plasma-facing wall; UDP: Upper dump plate; OPL: Outer poloidal limiter; IWC: Inner wall cladding; IWGL: Inner wall guard limiter; (b) colour-coded map of wall materials. The JET major radius is about $3 \mathrm{~m}$.

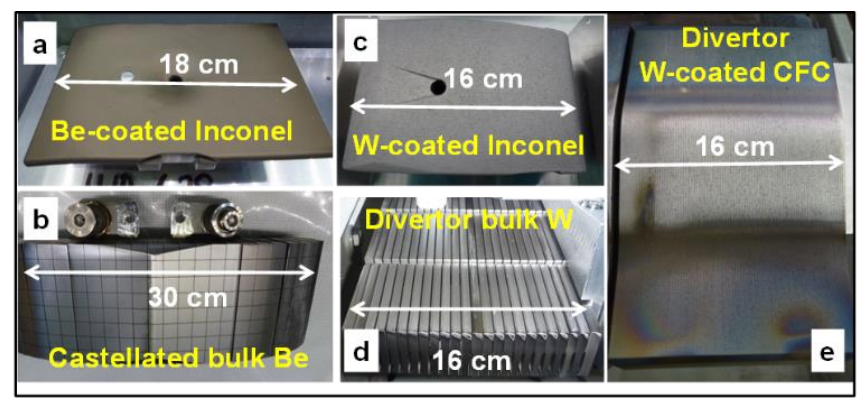

Figure 2. Examples of plasma-facing components from JET-ILW: (a) Beryllium coated Inconel tile from the inner wall cladding [81]; (b) segmented and castellated Be limiter tile [83]; (c) tungstencoated CFC; (d) bulk tungsten divertor tile from the divertor base [81]; (e) tungsten-coated carbon-fibre composite (CFC) tiles of the inner and outer divertor [81].

Examined samples are selected wall components (limiters, divertor plates including marker tiles) and dedicated tools for erosion-deposition studies such as wall probes [5], retrieved from the device after short-term exposures (single discharges or series of experiments) or after entire experimental campaigns lasting up to $1 \times 10^{5} \mathrm{~s}$. In detailed analyses of wall 
materials, the interest is in the determination of all species present in the reactor. These are hydrogen fuel isotopes $(\mathrm{H}$, $\mathrm{D}, \mathrm{T})$, helium $(\mathrm{He})$ originating either from the $\mathrm{D}-\mathrm{T}$ fusion reaction or as fueling gas, constituents of main PFCs $(\mathrm{C}, \mathrm{Be}$, $\mathrm{W}), \mathrm{Fe}, \mathrm{Cr}, \mathrm{Ni}, \mathrm{Mo}, \mathrm{Nb}$ as steel or Inconel components, elements used in plasma diagnostic systems $(\mathrm{Mg}, \mathrm{Al}, \mathrm{Si})$ and for wall conditioning $\left(\mathrm{He}, \mathrm{Li},{ }^{9} \mathrm{Be},{ }^{10} \mathrm{~B},{ }^{11} \mathrm{~B}, \mathrm{Si}\right)$, common impurities $(\mathrm{C}, \mathrm{O})$, gases seeded for plasma edge cooling $(\mathrm{N}$, $\mathrm{Ne}, \mathrm{Ar}, \mathrm{Kr}, \mathrm{Xe}$ ) and tracers for material migration introduced deliberately to the studied system in minute quantities $\left({ }^{6} \mathrm{Li}\right.$, ${ }^{7} \mathrm{Li},{ }^{10} \mathrm{Be} .{ }^{13} \mathrm{C},{ }^{15} \mathrm{~N},{ }^{18} \mathrm{O},{ }^{19} \mathrm{~F},{ }^{21} \mathrm{Ne},{ }^{22} \mathrm{Ne}$, Hf, Re etc.).

Over the years more than fifty different material research methods have been used for the analysis of PFCs and of probes exposed to plasmas in fusion devices and simulators of PWI. Accelerator-based IBA methods are crucial in this field due to their sensitivity, depth-profiling ability, and quantification without need for reference samples. The IBA family comprises nine major members: nuclear reaction analysis (NRA), elastic recoil detection analysis (ERDA) including high-energy heavy ion variants (HI-ERDA with e.g. incident $\left.\mathrm{C}^{\mathrm{n}+}, \quad \mathrm{Si}^{\mathrm{n}+}, \quad{ }^{127} \mathrm{I}^{\mathrm{n}+}, \quad \mathrm{Au}^{\mathrm{n}+}\right), \quad$ Rutherford backscattering spectrometry (RBS), non-Rutherford elastic backscattering spectrometry (EBS), medium energy ion scattering (MEIS), particle-induced X-ray and gamma-ray emission (PIXE and PIGE, respectively) and accelerator mass spectrometry (AMS). However, taking into account the large variety of used beam energies, projectiles, and beamtarget-detector geometries a huge number of widely used and very specifically tailored techniques is available. Their role has been very clearly proven in hundreds of analytical works from many laboratories involved in material studies from nearly all fusion devices around the world.

\section{Research capabilities: ion beam laboratories in studies of reactor materials}

A prerequisite for comprehensive material studies are well equipped laboratories, experienced staff, and international cooperations. The research capabilities of several accelerator laboratories working in the field of fusion materials are presented in this section. Main characteristics of the facilities are listed in Table 1; detailed descriptions are presented in sections A.1 - A.13 and schematic drawings of the facilities are shown in Figures A1 - A13 (only online version). It should be stressed that this listing comprises only facilities represented at the IAEA Technical Meeting and is not representing any quality rating in any order.

In addition to the facilities listed in Table 1 and described in sections A.1 to A.13 the following facilities are active in IBA for fusion research:

- Sandia National Laboratories, Albuquerque, New Mexico, USA [69].

- Massachusetts Institute of Technology, Plasma Science and Fusion Center, Cambridge, Massachusetts, USA [70-72].

- Fudan University, Institute of Modern Physics, Shanghai, China [73].

Facilities for ion induced radiation damage are related to IBA facilities, but have their own specifics and cannot be covered here completely. The following facilities are described in sections A.14 and A15:

- University of Huddersfield, MIAMI Facility, Huddersfield, United Kingdom [74], see section A.14 and Fig. A14.

- Argonne National Laboratory, IVEM-Tandem Facility, Illinois, USA [75-77], see section A.15 and Fig. A15.

Table 1. IBA facilities active in the analysis of samples from fusion devices and their analytical possibilities.

\begin{tabular}{|c|c|c|c|c|}
\hline Laboratory, Country & Accelerator & Available beams & Beamline & Methods available \\
\hline \multirow{10}{*}{$\begin{array}{l}\text { Uppsala University, } \\
\text { Tandem Laboratory, } \\
\text { Uppsala, Sweden } \\
{[6-12]}\end{array}$} & \multirow[t]{6}{*}{5 MV Tandem } & \multirow{6}{*}{$\begin{array}{l}\mathrm{H}, \mathrm{D},{ }^{3} \mathrm{He},{ }^{4} \mathrm{He}, \mathrm{Li} \text {, and } \\
\text { heavier ions }\end{array}$} & 1 & NRA (gamma \& particle), RBS \\
\hline & & & 2 & NRA, RBS, PIXE, $\mu$-beam \\
\hline & & & 3 & AMS tracer experiments for Be \\
\hline & & & 4 & $\begin{array}{l}\text { chamber 1: RBS, NRA (gamma \& particle), PIXE, TOF-ERDA; chamber } \\
\text { 2: RBS, NRA (gamma \& particle), PIXE, TOF-ERDA, large samples; } \\
\text { chamber 3: RBS, NRA for cross section measurements }\end{array}$ \\
\hline & & & 5 & irradiation: $2 \mathrm{MeV}$ to several ten $\mathrm{MeV}$ \\
\hline & & & 6 & in-situ growth and modification, RBS, NRA (gamma \& particle), PIXE \\
\hline & \multirow[t]{3}{*}{350 kV Implanter } & \multirow{3}{*}{$\begin{array}{l}\mathrm{H}, \mathrm{D},{ }^{3} \mathrm{He},{ }^{4} \mathrm{He}, \mathrm{Li} \text {, and } \\
\text { heavier ions including } \\
\text { molecular ion beams }\end{array}$} & 1 & implantation $>2 \mathrm{keV}$, broad range of elements, RT - $800 \mathrm{~K}$ \\
\hline & & & 2 & ToF-MEIS with 2 PSD-detectors \\
\hline & & & 3 & Low-energy HR-RBS \& NRA, irradiation, cryostatic detector \\
\hline & ToF-LEIS & $\begin{array}{l}\mathrm{H}, \mathrm{D},{ }^{3} \mathrm{He},{ }^{4} \mathrm{He}, \mathrm{Ne}, \mathrm{Ar} \\
\text { including molecular } \\
\text { ion beams }\end{array}$ & 1 & $\begin{array}{l}\text { ToF-LEIS with charge separation, AES, LEED, in-situ growth and } \\
\text { modification }\end{array}$ \\
\hline \multirow{6}{*}{$\begin{array}{l}\text { INPP, NCSR } \\
\text { "Demokritos", Tandem } \\
\text { Accelerator } \\
\text { Laboratory, Athens, } \\
\text { Greece } \\
\text { [13-15] }\end{array}$} & \multirow[t]{6}{*}{ 5.5 MV Tandem } & \multirow[t]{6}{*}{$\mathrm{H}, \mathrm{D}$ and heavier ions } & 1 & Nuclear Astrophysics, Hydrogen Profiling \\
\hline & & & 2 & $\mu$-beam \\
\hline & & & 3 & chamber 1: RBS, NRA, PIGE chamber 2: PIXE \\
\hline & & & 4 & $\begin{array}{l}\text { setup 1: gamma angular distribution turntable setup 2: goniometer } \\
\text { table for cross section measurements }\end{array}$ \\
\hline & & & 5 & Atomic Physics \\
\hline & & & 6 & $\begin{array}{l}\text { setup 1: fast neutron production setup } 2 \text { : Ion irradiation with in-situ } \\
\text { electrical Resistivity measurement }\end{array}$ \\
\hline
\end{tabular}




\begin{tabular}{|c|c|c|c|c|}
\hline $\begin{array}{l}\text { Instituto Superior } \\
\text { Técnico, Universidade } \\
\text { de Lisboa, Ion Beam } \\
\text { Laboratory, Lisbon, } \\
\text { Portugal } \\
\text { [16-20] }\end{array}$ & $\begin{array}{l}3 \text { MV Tandem } \\
\text { and } 2.5 \text { MV van } \\
\text { de Graaff }\end{array}$ & $\begin{array}{l}\mathrm{H},{ }^{3} \mathrm{He},{ }^{4} \mathrm{He} \text { and } \\
\text { heavier ions }\end{array}$ & $\begin{array}{l}1 \\
2 \\
3 \\
5\end{array}$ & $\begin{array}{l}\text { NRA (gamma \& particle), EBS/RBS, HRPIXE, Channeling, broad beam } \\
\text { NRA, RBS, PIXE, IL, STIM, } \mu \text {-beam (with external beam) } \\
\mu \text {-AMS optimised for heavy elements } \\
\text { irradiation: } 2 \mathrm{MeV} \text { - few ten MeV }\end{array}$ \\
\hline $\begin{array}{l}\text { CEA/Saclay, } \\
\text { Laboratory for Light } \\
\text { Element Studies (LEEL), } \\
\text { France } \\
{[21,22]}\end{array}$ & $\begin{array}{l}\text { 3.5 MeV single } \\
\text { ended van de } \\
\text { Graaff }\end{array}$ & $\mathrm{H}, \mathrm{D},{ }^{3} \mathrm{He},{ }^{4} \mathrm{He}$ & 1 & $\begin{array}{l}\mu \text { beam for PIXE, RBS, NRA, PIGE, ERDA, ERCS }+ \text { in situ low Energy } \\
\text { light ion implantation } \\
\mu \text {-beam for RBS, NRA, ERDA, Beamline dedicated to highly } \\
\text { radioactive samples (analysis chamber in a concrete cell; } \beta / \gamma \\
\text { emitters accepted, pure } \alpha \text { or neutron sources not allowed) }\end{array}$ \\
\hline \multirow{2}{*}{$\begin{array}{l}\text { Vinca Institute of } \\
\text { Nuclear Sciences, User } \\
\text { Facility for Irradiation } \\
\text { and Analysis of } \\
\text { Materials with Ion } \\
\text { Beams, Belgrad, Serbia } \\
{[23,156]}\end{array}$} & $\begin{array}{l}\text { CAPRICE: ECR ion } \\
\text { source. Heavy ion } \\
\text { beams: } 10-20 \\
\text { keV/amu; light } \\
\text { ions: } 15-30 \mathrm{keV}\end{array}$ & $\begin{array}{l}\mathrm{H}, \mathrm{D},{ }^{3} \mathrm{He},{ }^{4} \mathrm{He}, \mathrm{Li} \text {, and } \\
\text { heavier ions }\end{array}$ & & $\begin{array}{l}\text { Ion Beam Assisted Deposition (IBAD), Ion Bombardment } \\
\text { irradiation of polycrystalline targets in the temperature range from } \\
252 \text { to }+353 \mathrm{~K} \text {, and implantation of monocrystalline targets in the } \\
\text { temperature range from } 173 \text { to } 1273 \mathrm{~K}\end{array}$ \\
\hline & $\begin{array}{l}\text { Cyclotron, } \\
\text { energies } 1 \text { to } 3 \\
\text { MeV }\end{array}$ & $\mathrm{H}$ & & $\begin{array}{l}\text { The characteristics of the proton beam: energy precision - below } 1 \\
\text { keV; energy spread - below } 0.1 \% \text {; current } 10 \text { to } 100 \text { nA. } \\
\text { RBS,PIXE,NRA, PIPS Detector }(p, \alpha) \text {, Si X-Ray detector and cryostat }\end{array}$ \\
\hline \multirow[t]{3}{*}{$\begin{array}{l}\text { Forschungszentrum } \\
\text { Jülich, Tandetron } \\
\text { Laboratory, Jülich, } \\
\text { Germany } \\
{[24-27]}\end{array}$} & 1.7 MV Tandem & $\mathrm{H}, \mathrm{D},{ }^{3} \mathrm{He},{ }^{4} \mathrm{He}$ & $\begin{array}{l}2 \\
3\end{array}$ & $\begin{array}{l}\text { } \mu \text {-Beam, NRA, RBS, PIXE, PIGE, Irradiation: 0.5-3.5 MeV @350 nA, } \\
\text { temperature monitoring, electrical contacts, 4-point resistivity } \\
\text { measurement, non-flaking Be possible } \\
\text { free } \\
\text { TDS 77-1200 K, XPS, NRA, RBS, Plasma loading/implantation, AES, Be } \\
\text { compatible }\end{array}$ \\
\hline & $\begin{array}{l}15-30 \mathrm{MeV} \\
\text { Cyclotrons }\end{array}$ & $\mathrm{H}, \mathrm{D},{ }^{4} \mathrm{He}$ & 1 & $\begin{array}{l}\text { Irradiation: } 10 \text { to } 100 \mu \mathrm{A} / \mathrm{cm}^{2} \text {, temperature monitoring, remote } \\
\text { handling of extremely active samples }\end{array}$ \\
\hline & $\begin{array}{l}45-200 \mathrm{MeV} \\
\text { Cyclotron }\end{array}$ & $H, D$ & 1 & Irradiation: $1 \mu \mathrm{A} / \mathrm{cm}^{2}$, temperature monitoring, active samples \\
\hline $\begin{array}{l}\text { Maier-Leibnitz- } \\
\text { Laboratory (MLL), } \\
\text { Garching, Universität } \\
\text { der Bundeswehr } \\
\text { München, Neubiberg, } \\
\text { Germany } \\
{[28-30]}\end{array}$ & 14 MV Tandem & $\begin{array}{l}\mathrm{H}, \mathrm{D},{ }^{3} \mathrm{He},{ }^{4} \mathrm{He}, \mathrm{Li} \text {, and } \\
\text { heavier ions }\end{array}$ & $\begin{array}{l}2 \\
3\end{array}$ & $\begin{array}{l}\text { Microprobe SNAKE: pp, dd, pd-scattering (coincidence ERDA) } \\
\text { microscopy, high energy backscattering microscopy, transmission } \\
\text { geometry with sample thickness } 50 \text { to } 200 \mu \mathrm{m} \\
\text { Q3D Magnetspectrograph: heavy ion ERDA, high resolution ERDA } \\
\text { AMS: High-Energy AMS system with gas filled magnet system }\end{array}$ \\
\hline $\begin{array}{l}\text { Rudjer Boskovic } \\
\text { Institute, Tandem } \\
\text { Accelerator Facility, } \\
\text { Zagreb, Croatia } \\
\text { [31-36] }\end{array}$ & $\begin{array}{l}6 \text { MV Tandem } \\
\text { and } 1 \mathrm{MV} \\
\text { Tandetron }\end{array}$ & $\begin{array}{l}\mathrm{H},{ }^{3} \mathrm{He},{ }^{4} \mathrm{He}, \mathrm{Li} \text {, and } \\
\text { heavier ions }\end{array}$ & $\begin{array}{l}1 \\
2 \\
3\end{array}$ & $\begin{array}{l}\text { PIXE, PIGE, RBS (available with } 1 \text { MV Tandetron only) } \\
\text { in air PIXE (available with } 1 \mathrm{MV} \text { Tandetron only) } \\
\text { dual beam: focused ion beams (microprobe) from } 1 \mathrm{MV} \text { Tandetron, } \\
\text { broad beam from } 6 \mathrm{MV} \text { Tandem; ion beams available } \\
\text { simultaneously from both accelerators } \\
\text { dual beam irradiation chamber; ion beams available simultaneously } \\
\text { from both accelerators } \\
\text { Capillary MeV TOF-SIMS, ToF-ERDA } \\
\text { ion beams available from both accelerators } \\
\text { RBS/RBSc, PIXE/PIXEc (channeling), NRA, ion beams available from } \\
\text { one or the other accelerator } \\
\text { cross sections measurements, ion beams available from one or the } \\
\text { other accelerator } \\
\text { microprobe - RBS, PIXE, NRA, IBIC, HR-PIXE (with focused ion } \\
\text { beams), ion beams available from one or the other accelerator }\end{array}$ \\
\hline $\begin{array}{l}\text { Max-Planck-Institute } \\
\text { for Plasma Physics, } \\
\text { Tandem Laboratory, } \\
\text { Garching, Germany } \\
\text { [37-42] }\end{array}$ & 3 MV Tandem & $\begin{array}{l}\mathrm{H}, \mathrm{D},{ }^{3} \mathrm{He},{ }^{4} \mathrm{He}, \mathrm{Li} \text {, and } \\
\text { heavier ions }\end{array}$ & 1 & $\begin{array}{l}\text { Chamber 1: RBS, NRA, ERDA (with } \mathrm{He}, \mathrm{Li},{ }^{12} \mathrm{C},{ }^{16} \mathrm{O} \text { beams); Chamber } \\
\text { 2: RBS, NRA, PIGE, large samples } \leq 300 \times 200 \times 100 \mathrm{~mm}^{3} \\
\text { Chamber 1: Irradiation: } 200 \mathrm{keV} \text { to several } 10 \mathrm{MeV} \text {; Chamber 2: RBS, } \\
\text { NRA, ToF-RBS } \\
\text { RBS, NRA for sample sizes up to } 100 \times 20 \times 20 \mathrm{~mm}^{3} \text {, Glove box for Be } \\
\text { contaminated samples, T up to } 1 \mathrm{GBq} \\
\text { RBS, NRA, ERDA, in-situ irradiation and implantation with } 2 \text { ion } \\
\text { sources }\end{array}$ \\
\hline $\begin{array}{l}\text { Nuclear Science and } \\
\text { Technology Research } \\
\text { Institute, Van de } \\
\text { Graaff laboratory, } \\
\text { Teheran, Iran } \\
\text { [43-48] }\end{array}$ & $\begin{array}{l}3 \text { MV Van de } \\
\text { Graaff }\end{array}$ & $\begin{array}{l}\mathrm{H}, \mathrm{D},{ }^{4} \mathrm{He}, \mathrm{N} \text { including } \\
\text { molecular ion beams }\end{array}$ & $\begin{array}{l}1 \\
2 \\
3 \\
4\end{array}$ & $\begin{array}{l}\text { NRA (gamma \& particles), RBS } \\
\text { RBS-channeling, RBS } \\
\text { RBS, PIXE, NRA (particles) } \\
\text { Irradiation: } 300 \text { keV - } 3 \mathrm{MeV} / \text { External PIXE / K-edge contrast } \\
\text { Imaging / IL spectroscopy \& Microscopy } \\
\text { RBS, NRA (particles) } \\
\text { NRA, RBS, PIXE, IBIL, } \mu \text {-beam }\end{array}$ \\
\hline Jožef Stefan Institute, & 2 MV Tandem & $\mathrm{H},{ }^{3} \mathrm{He},{ }^{4} \mathrm{He}, \mathrm{Li}$ and & 1 & External ( $\mu$-beam) PIXE, PIGE, RBS \\
\hline
\end{tabular}




\begin{tabular}{|c|c|c|c|c|}
\hline $\begin{array}{l}\text { Microanalytical } \\
\text { Centre, Ljubljana, } \\
\text { Slovenia } \\
\text { [49-55] }\end{array}$ & & heavier beams & $\begin{array}{l}2 \\
3 \\
4\end{array}$ & $\begin{array}{l}\mu \text {-beam - PIXE, RBS, NRA, MeV-SIMS } \\
\text { in-situ D exposure/ thermal treatment; RBS, NRA, ERDA } \\
\text { High resolution XRS }\end{array}$ \\
\hline \multirow[t]{3}{*}{$\begin{array}{l}\text { Los Alamos National } \\
\text { Laboratory, Ion Beam } \\
\text { Materials Laboratory, } \\
\text { New Mexico, USA } \\
{[56-63,157]}\end{array}$} & $\begin{array}{l}3 \text { MV Pelletron } \\
\text { Tandem } \\
\text { Accelerator }\end{array}$ & $\begin{array}{l}\mathrm{H}, \mathrm{D},{ }^{3} \mathrm{He},{ }^{4} \mathrm{He} \text { and } \\
\text { heavier ions }\end{array}$ & $\begin{array}{l}3 \\
4 \\
5\end{array}$ & $\begin{array}{l}\text { Standard IBA techniques (RBS, NRA, ERD, PIXE, channeling). } \\
\text { Self-ion high temperature irradiation/implantation under LN2 to } \\
1000 \mathrm{C} \text {, ion irradiation and corrosion experiment } \\
\text { He implantation to simulate material compatibility in actinides } \\
\text { Alpha radiolysis research in solids, liquids, and gases } \\
\text { Dual-beam chamber between Tandem Accelerator and Varian } \\
\text { Impanter (LN2 to } 1523 \mathrm{~K} \text { ) }\end{array}$ \\
\hline & $\begin{array}{l}200 \text { kV Varian } \\
\text { Implanter }\end{array}$ & $\begin{array}{l}\text { Mainly gas ion } \\
\text { species }\end{array}$ & 1 & implantation/irradiation: $5 \mathrm{keV}$ to $200 \mathrm{keV}$ ions uder LN2 to $1250 \mathrm{C}$ \\
\hline & $\begin{array}{l}200 \text { kV Danfysik } \\
\text { Implanter }\end{array}$ & $\begin{array}{l}\text { Virtually any ions, } \\
\text { including metals }\end{array}$ & 1 & implantation/irradiation: $20 \mathrm{keV}$ to $800 \mathrm{keV}$ ions under LN2 to $500 \mathrm{C}$ \\
\hline \multirow[t]{2}{*}{$\begin{array}{l}\text { University of Helsinki, } \\
\text { Accelerator } \\
\text { Laboratory, Helsinki, } \\
\text { Finland } \\
\text { [64-68] }\end{array}$} & 5 MV Tandem & $\begin{array}{l}\mathrm{H}, \mathrm{D}, \mathrm{Li} \text {, and heavier } \\
\text { ions }\end{array}$ & $\begin{array}{l}1 \\
2 \\
3 \\
4\end{array}$ & $\begin{array}{l}\text { NRA (gamma \& particle), RBS } \\
\text { NRA, RBS, PIXE } \\
\text { AMS } \\
\text { chamber 1: RBS, NRA, PIXE, Tof-ERD; chamber 2: RBS, Stopper foil- } \\
\text { ERDA; chamber 3: PAS } \\
\text { irradiation: } 1 \text { MeV - several ten MeV }\end{array}$ \\
\hline & 500 kV Implanter & $\begin{array}{l}\mathrm{H}, \mathrm{D},{ }^{3} \mathrm{He},{ }^{4} \mathrm{He}, \mathrm{Li} \text {, and } \\
\text { heavier ions including } \\
\text { molecular ion beams }\end{array}$ & $\begin{array}{l}1 \\
2 \\
3\end{array}$ & $\begin{array}{l}\text { implantation }>100 \mathrm{eV} \text {, broad range of elements } \\
{ }^{3} \mathrm{He} \text { NRA } \\
\text { Low-energy RBS \& NRA, irradiation }\end{array}$ \\
\hline
\end{tabular}

\section{Specific issues in studies of fusion reactor materials}

There are a number of requirements in handling, transportation and analyses of fusion reactor materials. In addition, there are also serious restrictions in particular when working with materials originating from the JET tokamak with beryllium wall components and the presence of tritium related both to the operation with deuterium - tritium (D-T) fuel and produced in D-D nuclear reactions. Manual access is very limited. The removal, repair and replacement of selected tiles of PFCs and of erosion-deposition monitors is performed only during major shut-downs using a remotely handled (RH) robotic arm. All items retrieved from JET are transferred to the Beryllium Handling Facility (BeHF) at Culham Science Centre. All operations aiming at the dismantling, installation of items from the divertor modules or so-called wall brackets are carried-out in glove boxes by personnel wearing pressurized suits.

\subsection{Characteristic of wall components}

Obviously the entire surface area of a fusion device cannot be analysed due to time and cost constraints. For tokamaks with toroidal symmetry it is necessary to analyse at least one poloidal cross-section of the machine in order to be able to extrapolate to the whole machine. For tokamaks without toroidal symmetry (for example due to individual poloidal limiters) or stellarators (which do not have toroidal symmetry) multiple poloidal cross-sections may become necessary. Plasma-facing surfaces are typically made of separate wall tiles which can be dismounted and analysed individually. Although even single tiles may be large and heavy (see below), they are still much smaller than a whole component, such as a whole divertor section. Water-cooled components can be problematic because these cannot be removed without separation from the water feeds [78]. Decommissioned machines provide a vast amount of components for analysis [79], but the interpretation of data after very long exposures may be challenging.

In most cases material and manufacture of PFC tiles is expensive, therefore, these are often unique components without spares for replacement. Significant costs are also involved in the retrieval of tiles using remote handling systems. Therefore, the expenditure related to procurement and $\mathrm{RH}$ operation has to be taken into account in the planning of tile retrieval. Tiles without spares, if analysed exsitu, must be returned to JET for re-assembly during the same shut-down. For obvious reasons, cutting or any shapechanging sampling from such tiles is strictly excluded. This implies that dedicated surface analysis stations need to be equipped with chambers accommodating large and heavy items. For instance, the $\mathrm{W}$-coated CFC divertor tile shown in figure 2(e) has dimensions of $5 \times 16 \times 25 \mathrm{~cm}^{3}$ and a weight above $2 \mathrm{~kg}$. Hemispherical bulk tungsten test limiter tiles from the TEXTOR tokamak has a weight even above $8 \mathrm{~kg}$. Analyses of such components requires chambers with large loading ports and manipulators with long travel distance and potentially three-axis rotation.

A schematic drawing of a chamber housing several types of detectors used for IBA of large tiles is shown in figure $3(\mathrm{a})$, while figure 3 (b) shows a precision manipulator $(50 \mu \mathrm{m}$ accuracy) for handling heavy test limiters such as bulk tungsten and $\mathrm{B}_{4} \mathrm{C}$-coated copper presented in Fig. 3(c,d), respectively [80]. 


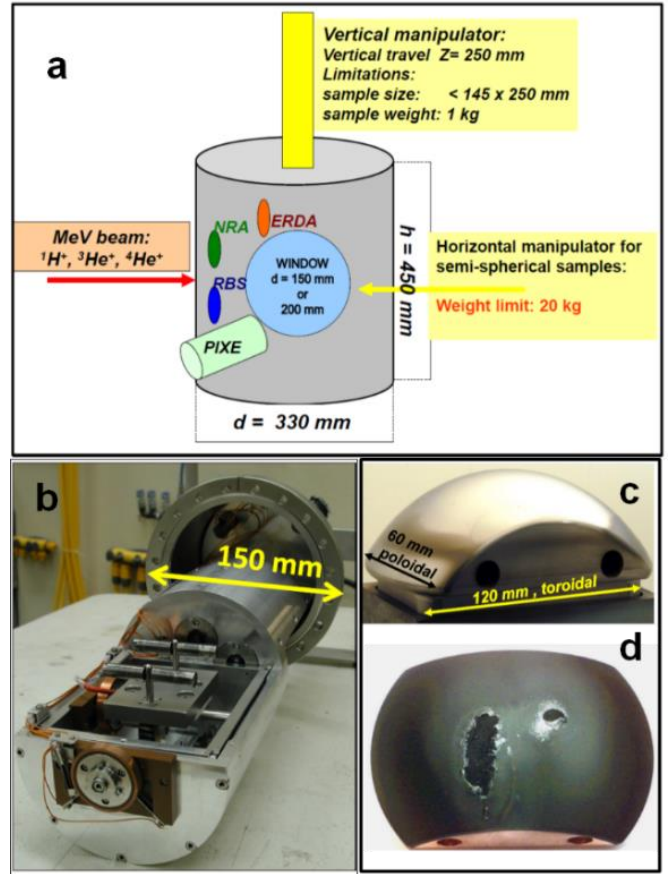

Figure 3. (a) Schematic drawing of a surface analysis station with the capability for handling large and heavy PFC tiles; (b) precision manipulator holding heavy test limiters [152] shown in (c) [155] and (d) [80]. The coating on the limiter in (d) has been partly molten.

Tiles which have spares can be sectioned to provide samples for different types of surface and bulk analyses. Cutting into small pieces reduces also the activity of samples to be handled in laboratories involved in studies of contaminated materials from JET [81]. This also allows very detailed high-resolution mapping by micro-beams, depth profiling, preparations of samples for transmission electron microprobes and, as result, it leads to conclusions on the overall material erosion-deposition pattern in a fusion device. W-coated CFC tiles are "cored" in the form of cylinders ( 8 or $18 \mathrm{~mm}$ in diameter). CFC coring procedures were developed in connection with the analyses of tiles after a full D-T campaign in JET, 1997-1998, when the activity of tritium accumulated in single tiles exceeded $100 \mathrm{GBq}$ [82]. Figure 4 shows a schematic drawing of a tile with two adjacent rows of cored samples: one set for the tritium determination by full combustion followed by scintillography of tritiated water and the other one for $\mathrm{D}, \mathrm{Be}, \mathrm{C}$ measurements with ${ }^{3} \mathrm{He}$-based NRA and metal impurities with RBS. The operation of JETILW called for the development of methodologies for beryllium, tungsten and Inconel cutting in order to provide samples for microscopy, IBA, thermal desorption etc. The metals are sawn under strict temperature control (infrared cameras, max. $60^{\circ} \mathrm{C}$ ) during that procedure to avoid desorption of hydrogen isotopes. Figure 5 provides details on the structure of the segmented castellated beryllium limiter tiles and their sectioning into single blocks of castellations in order to facilitate further detailed studies [83].

\subsection{Requirements for handling fusion materials}

The analysis of materials from fusion devices will necessarily require laboratories to handle some level of tritium, beryllium and/or activated samples. The presence of these hazards, particularly in combination, is problematic for many laboratories. However, experience of handling such samples has been gained from the plasma facing materials analysis programme at JET where beryllium has been used since 1990 and the first deuterium-tritium plasmas were performed in 1997 [84]. In 2010 the main chamber PFCs were exchanged for $\mathrm{Be}$ and the divertor PFCs for $\mathrm{W}$ to allow operations with an ITER-like wall configuration. This change increased the amount of $\mathrm{Be}$ to be handled for analysis. Due to the presence of beryllium, tritium and activated nuclides it is not acceptable to remove samples for analysis from JET on an $a d$ hoc basis, given that a significant amount of planning for the remote installation and removal of samples is needed. Specialised facilities are also required to recover the samples to make them available for analysis. At JET samples are handled in the Beryllium Handling Facility dedicated for working with beryllium and tritium contaminated components, as shown in figure 6 .

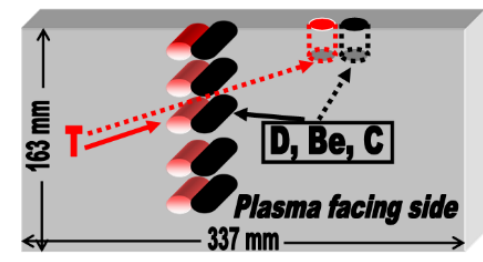

Figure 4. Schematic drawing of sectioning by coring large CFCbased divertor tiles from JET [152]. 


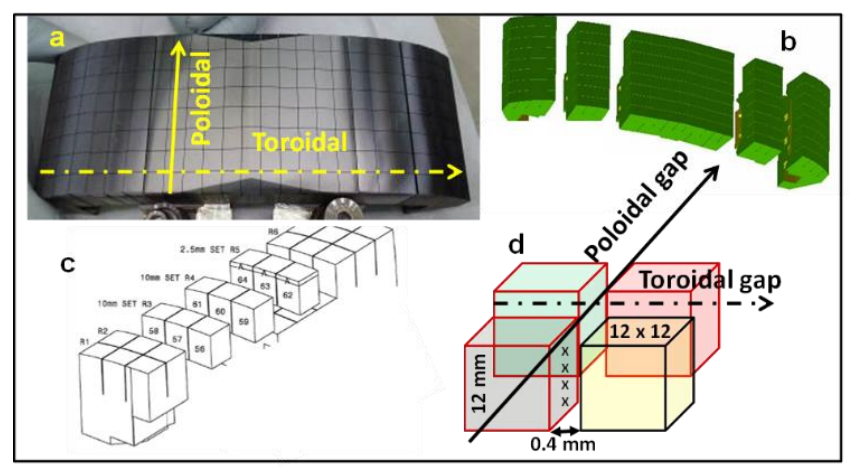

Figure 5. Details of the structure and sectioning of castellated beryllium limiters from JET: (a) appearance of the outer poloidal limiter and (b) the segmented tile structure; (c) sectioning and marking scheme of single blocks of castellation to enable microbeam analyses in the gaps (d). The analysis line is marked with X.

Therefore, to gain the most information from the analysis programme the complete cycle must be considered at the outset:

- sample planning - type of sample, exposure location, analysis aims;

- sample handling post exposure - size of samples, cutting, transport, contamination evaluation;

- ion beam facility capabilities - contamination containment, neutron shielding, radiation monitoring, beryllium monitoring.

\subsection{Sample planning}

The main aim of the analysis programme it to provide long term fuel retention and material erosion, migration and deposition assessment for fusion devices. The results provide insight into the physical processes of plasma wall interaction and results for benchmarking modelling codes. In order to facilitate the programme the analysis aims need to be well understood, this in turn guides the sample type and location in the vessel. The basic strategy is to analyse a set of representative plasma facing components. The analysis data from PFCs may be enhanced by using marker coatings deposited onto surfaces or by the injection of isotopically labelled gases at the end of the operating period as discussed in section 2. In the case of marker coatings the thickness of the coating must be analysed before and after exposure using backscattering techniques in order to determine erosion and deposition. Some lessons learned from JET highlight the need for choosing a material for the interlayer that is dissimilar from other species found in the local environment and also ensuring good adhesion of the coatings and matched thermal coefficient of expansion to decrease the risk of delamination from the PFC surface. The detection of the isotopes on PFC surfaces using IBA can be used to map migration from the injection point.

Specifically designed diagnostics aiming at providing time resolved erosion/deposition patterns [84], gross deposition and sticking coefficients [85] of deposited material have been deployed in fusion devices. Such diagnostics are typically installed in locations remote from the plasma, thus providing data on long range material migration to remote regions [86].

\subsection{Sample handling and facility capabilities}

To maintain a successful analysis programme of contaminated samples the participating laboratories need to have compatible infrastructure for sample handling. This is not only in respect of analysis but there may also be a need for resources in accounting and monitoring of radioactive materials and/or beryllium in order to transport and store samples.

In the case of analysis, glove boxes or containment isolators need to be attached to the analysis chamber to allow for the manipulation of contaminated samples. This type of containment is available at IST, Portugal, figure 7 and IPP Garching, Germany, figure 8. In the case of deuterium ion beam based Be samples analysis, additional shielding is required such that available at Demokritos, Greece, section A.2, and University of Helsinki, Finland, section A.13.

Within the JET analysis programme the only laboratory capable of routinely handling whole PFCs as shown in figure 2 , is at IST, Portugal, described in section A.3. The ability to handling these samples is due to the infrastructure at the site for accepting samples containing tritium and beryllium, the installation of a containment isolator on the chamber, see figure 7 , the size of the analysis chamber and ability to manipulate the component in the beam by $150 \mathrm{~mm}$ in height. An advantage of handling wholes tiles is that expensive components can be analysed non-destructively and returned to the machine. Analysis of whole components also avoids complicated reconstruction of data plotting arising from many smaller samples. 

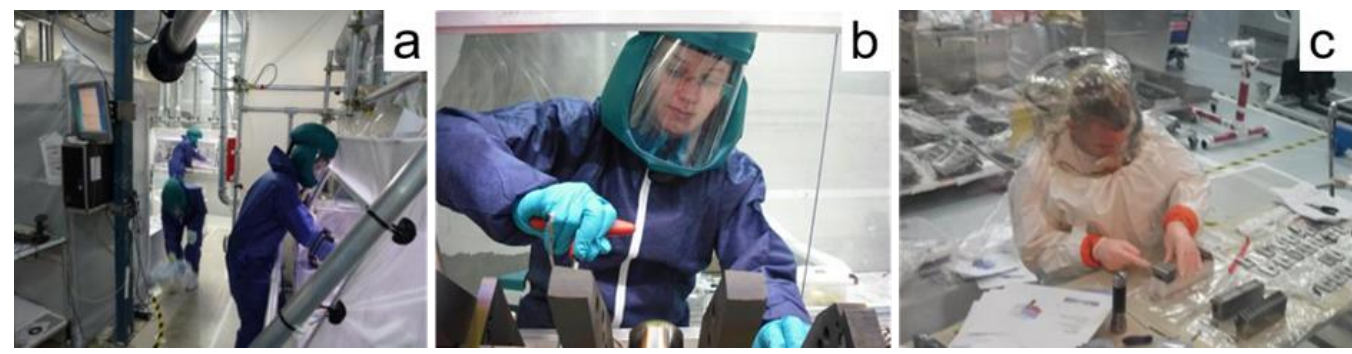

Figure 6. Operatives working in the Beryllium Handling Facility [81], a facility for supporting JET operation and maintenance. (a) and (b) Operative are wearing air inflated hoods equipped with a filter, disposable coveralls, rubber boots with overshoes and several pairs of gloves including a sacrificial top layer which is changed periodically. Work on JET components is carried out in ventilated slit boxes to minimise the spread of contamination and exposure to operatives. (c) Where it is not possible to work within a slit box, operatives wear a full containment suit with dedicated pressurised air supply.

However, to take advantage of the range of techniques offered by IBA it is necessary to provide smaller samples for analysis. The reduction in size not only allows the samples to be mounted at the analysis station but also reduces potential hazards associated with handling the sample. In the case of JET PFCs the radioactive inventory and beryllium levels of smaller samples are low enough to be accepted at participating laboratories and are relatively straightforward to transport in accordance with regulations. Depending on the size and number of samples it may still be necessary at some laboratories to provide containment at the analysis station, for example, as shown for IPP Garching in figure 8. Smaller samples can be in the form of specifically designed, easily removable tokens from larger components or samples cut from larger components. Current cutting capabilities are available for JET tiles consisting of tungsten coated carbon fibre composite, bulk beryllium and bulk tungsten. In all cases the methods are dry cutting techniques and temperature controlled to minimise the dissolution or desorption of fuel from the component [87].

With this type of infrastructure, capability for sample cutting and resources for controlling transport and on site monitoring, it has been possible to facilitate the analysis of beryllium and tritium contaminated samples from JET. However, based on the estimations of tritium inventories and activation in PFCs following JET deuterium-tritium operations, of neutron irradiated samples and of future fusion devices such as ITER will make sample transport and preparation significantly more demanding in terms of radiation safety. In these cases sampling handling and cutting facilities involving hot cells will be required.

\subsection{Analysis techniques and data analysis of JET samples}

Whilst in many respects samples share characteristics, in reality each sample is unique as it has been exposed to a wide variety of plasma operating conditions at its individual location and exposure time. Long and varied exposure to plasma means that the samples are highly inhomogeneous which places challenges on the IBA techniques employed for analysis. For example, the surface of PFCs may be fully covered with rough or smooth deposit, may be partially eroded or partially deposited or may have been melted. Deposits on the samples may be tens of microns thick and have inhomogeneous thickness, composition and density. The main techniques used to characterise these types of samples from JET are NRA and PIXE using the facilities at IST, Portugal (section A.3), and IPP Garching, Germany (section A.9). From this analysis depth profiles of deposits, fuel retention and erosion of marker coatings are studied. However, data analysis has to take into account the inhomogeneity of the sample, see section 6.1. HIERDA at Uppsala, Sweden (section A.1) and University of Helsinki, Finland (section A.13) is used mainly for smooth samples, such as on the dedicated passive diagnostic surfaces. Microbeam techniques at RBI, Croatia (section A.8) are useful for mapping inhomogeneities in deposits or small dust samples. Deuterium beam enables carbon and oxygen impurities to be evaluated in beryllium deposits. This analysis is carried out at Demokritos, Greece (section A.2).

With these targeted IBA techniques and data analysis the results provide insight into fuel retention and material migration. However, in order to achieve these results, data analysis must take into account the inhomogeneity of the samples, as discussed in sections 5 and 6 . This experience gained with JET is the basis for all other IBA activities for future fusion experiments such as W7-X or ITER. 


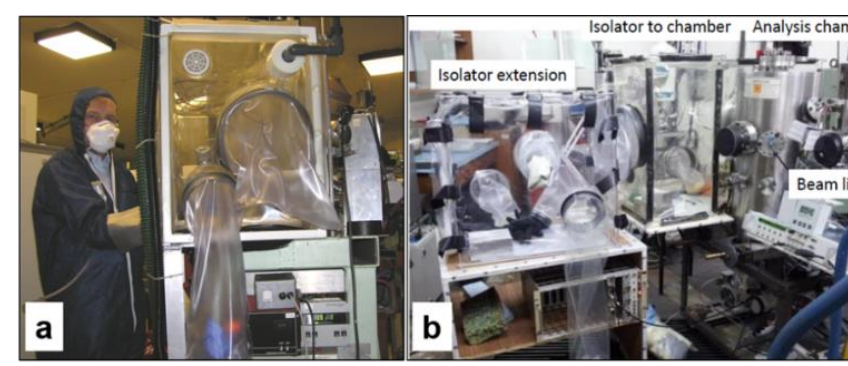

Figure 7. (a) Operative working at isolator loading samples into analysis chamber. (b) Analysis station at IST Lisbon showing analysis chamber with main isolator and extension for handling whole JET tiles contaminated with tritium and beryllium.

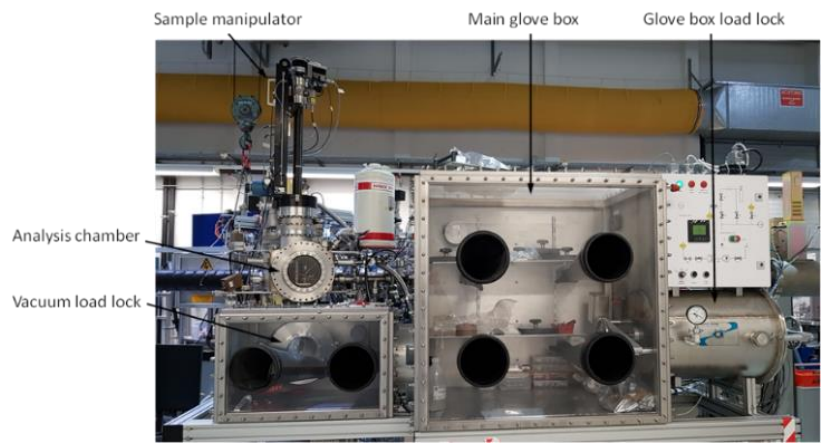

Figure 8. Glove box system at IPP Garching consisting of a glove box load lock, a main glove box for sample storage and handling, a secondary glove box for transferring samples to vacuum, a vacuum load lock between vacuum system and glove box, a sample manipulator for sample transfer between the vacuum load lock and the analysis chamber and for sample manipulation, and the analysis chamber with various detectors.

\subsection{Effects of air exposure}

The vast majority of IBA measurements of samples from fusion devices are performed ex-situ, i.e. the samples were stored for a typical time of several days to several months in air. The main reason are the huge technical difficulties associated with an IBA system in a reactor-class device keeping in mind the radiation field ( $\mathrm{n}, \mathrm{X}$ and gamma), the permanent magnetic field, temperature excursions of plasmafacing components, and difficulties to maintain/repair equipment. Moreover, in-situ IBA gives only information from a limited number of areas inside the vessel that are accessible by the incident ion beam and have free sight to the detector(s). An in-situ IBA system was used at Alcator-C Mod using an incident deuterium beam and detecting gamma radiation (PIGE) [71,72].

In-vacuo analysis has been employed at JET by the Fast Transfer System allowing the transfer of samples from the JET vessel to accelerator laboratories under vacuum. However, the high technical complexity made the use of this system very difficult and highly impractical. As a result, it was used only on very rare occasions [88]. A vacuum "suitcase" allowing the transfer of a sample in vacuum from the ASDEX Upgrade midplane manipulator to the SAK analysis station was foreseen at ASDEX Upgrade [89], but, to our knowledge, was never used.

However, in-situ IBA is used in a number of laboratory experiments for simulating specific aspects of PSI processes (e.g. [90]).

Many results are not affected by exposure to ambient atmosphere at all: For example the amounts of eroded or deposited solid materials (such as beryllium, carbon or tungsten) are not altered by air exposure. These data provide important information about erosion/deposition processes, material transport and component lifetime. The major risks of material exposure to ambient atmosphere are related to: (i) isotope exchange of deuterium or tritium by hydrogen from water vapour present in humid air and (ii) oxygen reaction with surfaces.

(i) The instant release or isotope exchange of hydrogen isotopes under contact of PFCs with ambient atmosphere cannot be excluded. For practical reasons the shortest time between the exposure and analysis are several hours. The retention data obtained after that time and a few days later were identical [91]. There were also exercises of measuring the same sample after a few years of storage, and a decrease by $25 \%$ was observed after 5 years [91]. The deuterium content of a deuterated amorphous hydrocarbon layer was stable within the measurement uncertainties during 8 years of storage in ambient atmosphere [92], while the D content of a sample from ASDEX Upgrade decreased by a factor of about 2 within roughly 1 year [92]. A radiation-damaged W sample was implanted by $8 \mathrm{eV} \mathrm{D}$ ions at $370 \mathrm{~K}$, the D-content decreased by less than $15 \%$ during a storage time of 1.5 years [93]. If a massive release occurs, it probably happens immediately after air ingress. For that reason IBA data are compared with the global gas balance which indicated the retention to be 30-50\% larger than that obtained with ex-situ IBA [94]. Depending on material structure the release of hydrogen isotopes from samples from fusion devices can be an issue, but according to current knowledge this release is assumed to be relatively slow. Laboratory samples are usually stable over long periods of time.

(ii) Oxidation of surfaces and/or uptake of water molecules from humid air is an issue. Therefore the interpretation of the oxygen and protium signals has to be very carefully. Comparison to reference samples and laboratory experiments can help to determine the effect of oxidation.

\section{Simulation Programmes}

Except for very simple cases the calculation of damageand implantation profiles or the quantitative evaluation of IBA spectra requires the use of simulation software. Many codes dedicated for calculating energetic ion-solid interactions, IBA spectrum simulation and quantitative IBA 
data analysis have been developed over the last decades. It is beyond the scope of this paper to review all of them, a short overview of codes relevant for fusion research is given below.

Molecular Dynamics (MD): MD calculates the time evolution of trajectories of a set of interacting atoms by numerical integration of Newton's equation of motion [95]. The forces between the particles and their potential energies are determined using interatomic potentials, the time steps are typically of the order of a few fs each. MD simulations are very close to physical reality but require long computing times and are usually limited to short timescales below $1 \mu \mathrm{s}$. In materials science $\mathrm{MD}$ is used for calculating various aspects of radiation damage by energetic ions [96], ion ranges in materials [97], and ion channelling [98]. Multiple molecular dynamics software packages with similar core functionality are available.

Monte Carlo (MC) with binary collision approximation (BCA): In BCA the trajectory of an energetic ion in a material is approximated by a sequence of independent binary collisions with sample atoms; the ion trajectory between these collisions is assumed to be straight and experiencing electronic energy loss but no further collisions with nuclei [99]. BCA simulations are much faster than MD simulations, but are limited to higher energies due to the neglect of many-body interactions taken into account by MD. The target structure is often assumed to be amorphous. BCA simulations are a common tool for calculating reflection, sputtering, radiation damage and ion ranges in materials. $\mathrm{MC}$ with $\mathrm{BCA}$ is generally too slow for analysing IBA energy spectra on a regular basis but has been used for calculating MEIS [100] or RBS spectra in special cases [101]. The most popular BCA code is SRIM [102], but different codes (for example SDTrim.SP [103]) are available and may offer improved accuracy [104].

MC with BCA and weight function: This family of codes is optimised for fast calculation of RBS and ERDA energy spectra including accurate simulation of plural (large angle) and multiple (small angle) scattering effects. In contract to classical MC with BCA these codes do not calculate individual particles, but ensembles of particles using MC summing up probabilities instead of single particles for obtaining the energy spectra. Only particles with sufficiently high probability to reach the detector are followed, and a much larger detector than the real one ('virtual detector') can be used. These codes are typically several orders of magnitude faster than MC with BCA codes and fast enough for calculating RBS and ERDA spectra on a regular basis, available codes are MCERD [105,106] and CORTEO [107].

Analytical codes: This family of codes approximates the trajectories of incident and exit particles by straight lines connected by a single scattering or reaction event, incident and exit particles experience electronic and nuclear energy loss and energy loss straggling on their trajectories. Modern codes approximate multiple scattering effects as energy spread [108]; plural scattering is approximated in the dual scattering approximation [101]. Many different codes exist in this family and have been reviewed in [109]. Codes typically include data bases for different stopping and straggling models and sometimes incorporate data bases for nonRutherford scattering, nuclear reaction and PIGE crosssections. Sample effects like porosity or various surface roughnesses and detector effects like geometrical straggling, dead time or pulse pile-up can be included in simulations. These codes are generally very fast and are regularly used for evaluating RBS, EBS, ERDA, NRA, MEIS, and PIGE spectra. Popular codes are SIMNRA [1110,111], NDF with graphical user interface WiNDF [112], and RUMP [113]. An intercomparison of analytical codes was presented in $[114,115]$ and showed very good agreement.

Self-consistent analysis of multiple measurements: Complex samples with multiple elements often require the analysis of multiple measurements using different methods and/or different energies or geometries. This analysis should be self-consistent, i.e. a unique sample structure should be used for all simulations. NDF/WiNDF [112] and MultiSIMNRA [116] provide self-consistent analysis of multiple IBA measurements, NRADC [117] has been developed for depth-profiling of deuterium using measurements at different energies. SIMNRA [110,111] offers full access to its functionality through COM/OLE interfaces, thus allowing automated data processing.

Codes for 2- and 3-dimensional samples: Samples with artificial surface structures (e.g. periodic gratings [118]), extreme surface roughnesses (e.g. tungsten fuzz [119]), or heterogeneous materials [120] require specialized codes. SDTrimSP-2D [121] is a MC code with BCA allowing calculating the evolution of 2-dimensional targets by implantation and sputtering [113]. CORTEO [107] allows calculating IBA spectra from arbitrary 2-dimensional or 3dimensional material distributions [122]; STRUCTNRA [123] calculates IBA spectra from arbitrary 2-dimensional distributions. A recent inter-comparison of different codes showed very good agreement among the codes and with experimental data [124].

Samples from fusion experiments are often highly challenging for all analysis methods including ion beam analysis: In many cases low- $Z$ and high- $Z$ elements are present in the samples, requiring multiple measurements with different techniques (for example RBS for high-Z elements, NRA for low-Z elements, and PIXE/PIGE for trace elements) and self-consistent data analysis. The required depth of analysis can exceed several $10 \mu \mathrm{m}$ : RBS measurements then need high-energetic protons with energies above $3 \mathrm{MeV}$. The scattering cross-sections are non- 
Rutherford for all lower-Z elements at these energies, while the presence of high- $Z$ elements can result in distinct multiple and plural scattering effects. Redeposited and eroded layers can be laterally inhomogeneous, both with respect to layer thickness and composition. Sample surfaces are often technically rough, in some cases carbon-fibre composite (CFC) surfaces with very high roughnesses are to be analysed. The number of measured spectra can exceed several thousand, setting limits to the possibilities of manual data analysis and requiring automatic procedures with as little manual intervention as possible.

These challenges raised by the analytical needs of fusion materials have been strong driving forces for simulation program developments: SDTrimSP was developed for calculating erosion yields and reflection coefficients for plasma-surface interaction research in fusion devices. The SIMNRA code was initially developed to cover the analytical needs of IBA in fusion devices; the development of surface roughness algorithms [125] was triggered by the rough surfaces found on samples from JET. ERDA measurements of helium in tungsten fuzz [126,127] were the starting point for the development of the STRUCTNRA code [123].

The computer simulation of ion beam analysis methods is highly developed and able to provide quantitative results even for highly complex samples, while inter-comparisons of various codes (often organized by the IAEA) demonstrated the principal correctness of these codes.

\section{Challenges for quantitative IBA analysis of fusion materials}

This chapter discusses a number of issues for IBA of fusion materials. Many of these issues are general problems of IBA, but some of them are more severe in the fusion context due to particular materials such as Be and D investigated in fusion research and the high degree of international cooperation.

The following recommendations arise from goals of enabling analysis of all relevant isotopes and elements present in current nuclear fusion concepts and finding all inter-laboratory results of the same samples within their respective error bars. Comparisons and joint experiments were carried out in the past, but so far a solid value for the international repeatability of IBA results is not available. Deviations in the results could lead to false conclusions of expensive experimental campaigns. Missing analysis capabilities increase cost and reduce result quality.

\subsection{Complex samples}

RBS spectra from rough Mo/W layers on top of $\mathrm{W}$ are shown in Fig. 9. Such layer structures have been used for erosion/deposition studies in JET [128,129]. Both examples are challenging due to the large analysed thickness of more than $15 \mu \mathrm{m}$ of high-Z elements, resulting in visible multiple- and plural scattering effects (dotted lines), and due to the roughness of the substrate and the layers. The spectrum on the left sample can be simulated accurately (solid line), except channel numbers below about 200 where minor deviations between the experimental data and the simulation are observed. The simulation of the spectrum from the right sample requires an additional Lorentzian substrate roughness of $50^{\circ} \mathrm{FWHM}$. The simulation still reproduces the main features of this spectrum, allowing extracting the mean thicknesses of the Mo and W layers. However, some details of the experimental spectrum are not well reproduced, so that this very complex rough sample marks the current limits of the simulation of inhomogeneous, rough samples. A simple simulation assuming smooth layers and without plural scattering (dashed lines) poorly reproduces the experimental spectra.

The influence of various types of surface roughness on the determination of depth profiles and total amounts of elements was investigated in [123] by computer simulations. It was concluded that roughness and depth profiles are generally ambiguous, but "total amounts of elements can be derived with some robustness from count integrals. For moderate roughness, not too large energy losses and sufficiently smooth cross-sections count integrals allow to determine total amounts of elements with an uncertainty of the order of less than $10 \%$."

The analysis of solidified melt zones, as shown in Fig. 3(d), is generally possible, but not straightforward and no user-ready recipes exist. This relates to the fact that melt damage may change the chemical composition, surface roughness and structure including the formation of cracks under heat loads. The effect of continued plasma exposure on intentionally melt-damaged divertor tiles was studied recently in ASDEX Upgrade and resulted in a microscopically very inhomogeneous erosion/deposition pattern on the corrugated pre-damaged surface. Net erosion was observed at surface areas oriented towards the incident plasma flux and net deposition in shadowed areas [131]. Moreover, the surface composition may be further modified by the exposure history after the damage had occurred. Therefore, individual approaches must be applied in studies of melt zones.

\subsection{Input data for IBA}

IBA measurements are indirect measurements, primarily yielding reaction probability spectra. The determination of the underlying sample composition and structure relies on the interpretation of these spectra via physical models as discussed in section 5 requiring additional input data. The accuracy of these input data therefore limits the accuracy of the IBA results, requiring precise input data on:

- Stopping powers;

- Energy straggling; 
- Cross-section data for non-Rutherford scattering and nuclear reactions.

For the stopping power a solid physical understanding exists for energies above a few $100 \mathrm{keV} / \mathrm{amu}$ with the BetheBloch equation. Additional corrections and fits to experimental data, in particular with the SRIM code $[102,132]$, provide an accuracy of $4.0 \%$ for protons and deuterons, $3.9 \%$ for $\mathrm{He}$ isotopes, $4.8 \%$ for $\mathrm{Li}$, and $5.8 \%$ for other ions in single-elemental targets [132]. These values are averaged over all elemental targets. However, the uncertainties are usually higher at energies in the region of the stopping power maximum and below and can exceed the overall inaccuracies given above. For a number of elements (e.g. transition metals) experimental stopping-power data can be very scarce or non-existent [133], resulting in larger (but hardly quantifiable) inaccuracies. Also for elements with interest to fusion the experimental data base is sometimes very poor: For $\mathrm{He}$ in $\mathrm{Mo}$ or $\mathrm{W}$ there are only 2 experimental data sets, respectively, in the region of the stopping power maximum. These deviate by $10-20 \%$ with the SRIM data lying in between [134].

Moreover, deposited layers in fusion devices typically contain a mixture of all elements present in the device: This material has sometimes been called tokamakium [135]. As experimental data on stopping powers in these mixed materials are extremely scarce or even non-existing, the stopping powers of these compounds have to be determined assuming a linear combination of the stopping contributions of all elements called 'Bragg's rule' [136]. This is normally done automatically by the analysis software but can get problematic if the layers contain large concentrations of carbon together with hydrogen isotopes, because deviations from Bragg's rule of $10-20 \%$ have been observed in hydrocarbon materials including amorphous hydrocarbon layers [137]. Similar deviations from Bragg's rule have also been observed in carbides, nitrides and oxides [138]. Simulation software often allow taking deviations from Bragg's rule into account using an ad-hoc correction factor. This problem is somewhat relaxed in today's fusion devices with metallic walls, because deviations from Bragg's rule are assumed to be small (typically $<2 \%$ ) in metallic compounds and alloys [139], and also in compounds containing heavier atoms such as $\mathrm{Fe}_{2} \mathrm{O}_{3}, \mathrm{NbC}, \mathrm{NbN}, \mathrm{Ta}_{2} \mathrm{O}_{5}, \mathrm{WO}_{3}$ [138].

Inaccuracies of stopping powers have a direct influence on the accuracies of derived elemental concentration profiles. For large samples an accurate measurement of the incident ion beam current is generally difficult, and the integrated charge is then often determined from a fit to the bulk spectrum. In this case, inaccuracies of the bulk stopping powers may have direct consequences also for the determination of total amounts of elements.

The slowing down of ions is always associated with energy straggling. Precise energy straggling data are required for a correct description of the low-energy edge of smooth layers, for modelling the correct shape of spectra with narrow peaks in the cross-section, and for depth resolution calculations. Electronic energy loss straggling can be calculated using Bohr's theory [140] with corrections for electron binding [141] and charge-state fluctuations [142] in order to achieve sufficient accuracy. For high-Z elements the energy spread introduced by multiple small-angle scattering can get important, an analytical theory of multiple scattering is presented in [108] and was shown to be in good agreement with MD and MC [143]. Geometrical energy spread introduced by finite beam spot size and detector aperture width can be treated analytically [108]. Overall, despite the general wish for more accurate data, the accuracy of straggling data is considered sufficient for the purposes of fusion investigations, where often surface or layer roughness dominate energy spread.

For the reaction cross-sections a fundamental physical model does not exist, hence these data have to be determined experimentally. Semi-empirical fitting models using Rmatrix theory are available; here in particular the SigmaCalc [144] code is established in the IBA community, allowing for cross-section data interpolation if a sufficient amount of the 2D space of $E$ and $\theta$ has been determined experimentally for a specific reaction with sufficiently high accuracy. This situation is desired as it allows for improved data quality via the combination of data involved in the fitting process and allows for corrections of detector size and position specific to the individual setups.

Currently the database of cross-sections is particular fragmentary for fusion materials. One example for the case of $\mathrm{Be}$ is demonstrated in figure 10 . The $\mathrm{p}_{0}$ and $\mathrm{p}_{1}$ peaks from the ${ }^{9} \mathrm{Be}\left({ }^{3} \mathrm{He}, \mathrm{p}_{\mathrm{x}}\right)^{11} \mathrm{~B}$ reaction are reproduced accurately in the simulation, but the remaining 9 lower-energy peaks cannot be simulated due to missing cross-section data. The decay of ${ }^{8} \mathrm{Be}$ (produced in the ${ }^{9} \mathrm{Be}\left({ }^{3} \mathrm{He}, \alpha_{\mathrm{x}}\right)^{8} \mathrm{Be}$ reaction) into $2 \alpha$ 's results in an additional background which cannot be simulated correctly. For the analysis of deuterium retention using the $\mathrm{D}\left({ }^{3} \mathrm{He}, \mathrm{p}\right)^{4} \mathrm{He}$ nuclear reaction the angular distribution of the reaction products is almost isotropic in the center-of-mass system at ${ }^{3} \mathrm{He}$ energies below about $1200 \mathrm{keV}$ [145]. At higher energies good datasets exist only for $\theta=135^{\circ}, 144.5^{\circ}$ and $175^{\circ}[146,147]$. Due to the lack of easily available alternatives, these datasets are widely applied even for different reaction angles. This practice leads to unknown systematic errors of the results in quantity and depth distribution.

In conclusion, on the basis of the cross-section data contained in IBANDL the authors identified the need for determining the cross-sections for $\mathrm{D}, \mathrm{Li}, \mathrm{Be}, \mathrm{C}, \mathrm{N}, \mathrm{O}$ analysis (including all stable isotopes) with ${ }^{3} \mathrm{He}$ for angles of 120 $175^{\circ}$ and energies up to $6 \mathrm{MeV}$ and the cross-sections for $\mathrm{Li}$ and $\mathrm{Be}$ analysis with protons for angles of $120-175^{\circ}$ and 
energies up to $4.5 \mathrm{MeV}$. Furthermore, the determination of stopping powers for specific fusion materials such as $\mathrm{W}$ in particular at low energies and up to $5 \mathrm{MeV}$ protons and helium ions and for heavy ions (used in ERD) is recommended.
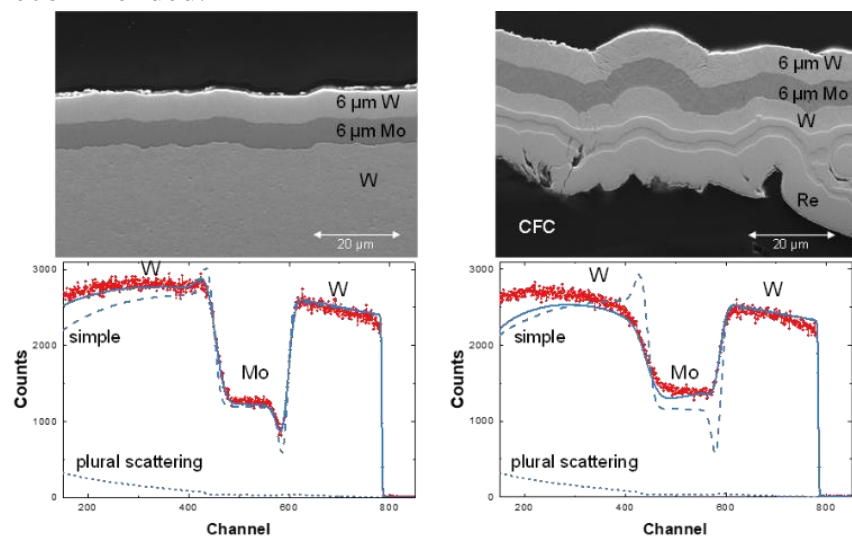

Figure 9. Top left: Cross-section of $6 \mu \mathrm{m}$ Mo and W layers on bulk W. Top right: Cross-section of carbon-fibre composite (CFC) material, coated with a $14 \mu \mathrm{m}$ Re and W layer, $6 \mu \mathrm{m}$ Mo, and $6 \mu \mathrm{m}$ W. Bottom: Experimental and simulated RBS spectra, measured with $4 \mathrm{MeV}$ protons, backscattering angle $165^{\circ}$, normal incidence. Dashed line - simple simulation with smooth layers and without plural scattering; Dotted line - plural scattering contribution; Solid line - Simulation including substrate roughness (in the case of $\mathrm{CFC}$ ), layer roughness, multiple and plural scattering. Simulations by SIMNRA [111,125]. Modified from [130].

${ }^{3} \mathrm{He}$-based NRA is a major tool for the quantification and depth profiling of deuterium in PFCs [37-39,148] and in analyses of mixed materials containing deuterium, carbon $\left({ }^{12} \mathrm{C},{ }^{13} \mathrm{C}\right)$ and beryllium [149], as well as other low-Z species such as boron and nitrogen. Unfortunately, in studies carried out on beryllium substrates or Be-rich layers even a qualitative determination of the presence of carbon poses serious difficulties. While beryllium is of great importance as wall material for ITER and the metal is used in JET-ILW (see Chapter 2), the application of carbon is not foreseen in ITER [152] because of predicted unacceptable levels of tritium inventory [4,151,152]. However, carbon impurities are always present in vacuum systems and in many materials and eventually may have decisive impact on the retention. Therefore, a proper discrimination between beryllium and carbon is the prerequisite for accurate carbon quantification.

In figure 11 spectra of pure carbon and beryllium are shown for NRA with $3 \mathrm{MeV}^{3} \mathrm{He}$ at $170^{\circ}$. In situations where the amount of $\mathrm{C}$ dominates over the $\mathrm{Be}$ content both elements can be easily distinguished because the $\mathrm{Be}$ concentration can be calculated from the high energy peaks. The $\mathrm{C}$ content is then calculated from the carbon peaks after subtraction of the beryllium background. In the reverse case the situation is much more complex as already small uncertainties in the beryllium cross-section will dominate over the carbon signal in the regions where peaks of both elements coincide. Because the cross-section varies, it is especially difficult to ensure proper background subtractions for thicker samples where the cross-section and/or the concentration will vary dependent on the depth in the sample.

In some situations (i.e. small amounts of $\mathrm{C}$ distributed in a Be matrix) it will always be very difficult to perform this type of analysis but having a more reliable data set on Be cross-sections will increase also the sensitivity for carbon detection. For the ${ }^{12} \mathrm{C}\left({ }^{3} \mathrm{He}, \mathrm{p}_{\mathrm{x}}\right){ }^{14} \mathrm{~N}$ reaction IBANDL contains cross-section data at $165^{\circ}$ for ${ }^{12} \mathrm{C}\left({ }^{3} \mathrm{He}, \mathrm{p}_{0}\right){ }^{14} \mathrm{~N}$; data at $160^{\circ}$, $150^{\circ}, 120^{\circ}$ and $90^{\circ}$ for ${ }^{12} \mathrm{C}\left({ }^{3} \mathrm{He}, \mathrm{p}_{0,1,2}\right)^{14} \mathrm{~N}$; and at $177^{\circ}$ for ${ }^{12} \mathrm{C}\left({ }^{3} \mathrm{He}, \mathrm{p}_{1,2}\right){ }^{14} \mathrm{~N}$ in a relatively narrow energy range. The agreement of the different data sets is poor. For the reaction ${ }^{9} \mathrm{Be}\left({ }^{3} \mathrm{He}, \mathrm{p}\right){ }^{11} \mathrm{~B}$, IBANDL comprises cross-section values only for three angles: $150^{\circ}, 135^{\circ}, 90^{\circ}$. In several analyses systems higher angles (such as $165^{\circ}$ and $170^{\circ}$ ) are used. A larger selection of angles would provide more possibilities for the optimisation of measurements.

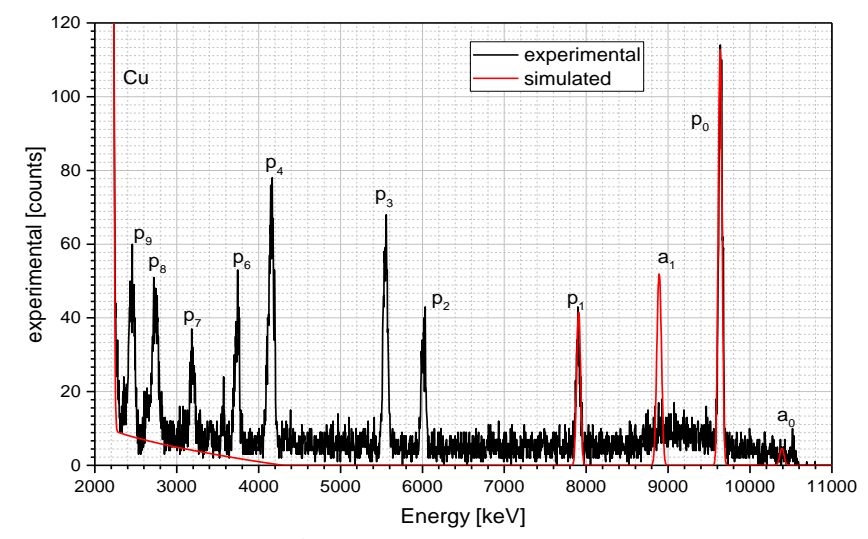

Figure 10. $2.95 \mathrm{MeV}{ }^{3} \mathrm{He}$ NRA/RBS analysis of a $1 \mu \mathrm{m}$ thick Be film on $\mathrm{Cu}$ measured with a $1500 \mu \mathrm{m}$ thick Si-Detector at $165^{\circ}$. SimNRA 7.01 analysis in red. Reaction products of ${ }^{9} \mathrm{Be}\left({ }^{3} \mathrm{He}, \mathrm{p}_{\mathrm{x}}\right){ }^{11} \mathrm{~B}$ and ${ }^{9} \mathrm{Be}\left({ }^{3} \mathrm{He}, \alpha_{\mathrm{x}}\right)^{8} \mathrm{Be}$ reactions are observed. From right to left $\alpha_{0}$, $\mathrm{p}_{0}$, $\alpha_{1}, p_{1}, p_{2}, p_{3}, p_{4}, p_{6}, p_{7}, p_{8}, p_{9}, C u$ RBS edge. Literature data on $p_{0}$ and $\mathrm{p}_{1}$ well describe the measurement, but the other peaks are missing. ${ }^{8} \mathrm{Be}$ decay produced by the $\alpha$-reactions induced an isotropic emission background.

Simultaneous quantification and depth profiling of Be and $\mathrm{C}$ can be performed by HIERDA, but the information depth is limited to several hundreds of nanometres. ERDA methods often require larger sample sizes and are difficult to use with $\mu$-beams. Moreover, ERDA is very sensitive to the sample surface finishing due to the analysing beam grazing incidence requirement. Quantification of $\mathrm{C}$ in low-Z mixtures on beryllium has been achieved by means of deuteriumbased NRA [153,154], but also in this case a comprehensive library of cross-sections would be beneficial.

Using higher incident energies increases the depth of analysis, but renders the availability of cross-section data even more difficult. Large depths of analysis can be achieved for example by combining IBA and SIMS or by crosssectioning methods; TDS can deliver information about the 
total amount of trapped hydrogen isotopes throughout the whole sample depth.

\subsection{Standards}

IBA work for fusion relies on sample analysis in numerous independent scientific institutions. Most of the applied devices are at least partially custom-made. Additionally, the quantitative evaluation of IBA measurements involves at larger number of manual adjustments (such as the selection of regions of interest) and the selection of input data (such as stopping powers or cross-section data). The ongoing developments of devices, analysis schemes/software, and input data, have led to a diverse situation where each laboratory (and sometimes even each researcher) uses different procedures for energy calibration, solid angle calibration, incident beam current measurement and data evaluation. This lack of standard procedures potentially leads to different results when analysing identical samples in different institutions. Potentially even the evaluation of the same raw IBA spectrum will lead to different results when performed by different scientists.

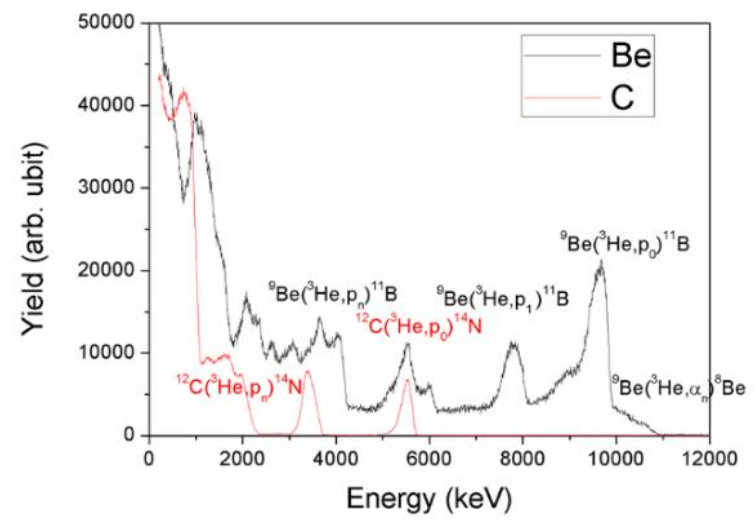

Figure 11. Spectra recorded with $3 \mathrm{MeV}{ }^{3} \mathrm{He}+$ for pure carbon ${ }^{12} \mathrm{C}\left({ }^{3} \mathrm{He}, \mathrm{p}\right){ }^{14} \mathrm{~N}$ and beryllium ${ }^{9} \mathrm{Be}\left({ }^{3} \mathrm{He}, \mathrm{p}\right){ }^{11} \mathrm{~B}$, scattering angle $170^{\circ}$.

The analysis of data taken by means of IBA techniques involves several steps. Figure 12 demonstrates difficulties in selecting appropriate cross-sections in a situation where data exist. The four datasets disagree up to a factor 50 at practically identical reaction angles. Even if the analysis of $\mathrm{C}$ is not based on this elastic scattering, the contributions have to be taken into account as background for other reactions and for pile-up calculations.

In SIMNRA, NDF or other evaluation suites about 20 different calculation options exist for data analysis with potential strong influence on computing time and final results. In particular the applied stopping powers can introduce significant differences. The indirect nature of IBA measurements leads to the requirement of fitting procedures. This fitting can be executed manually or automatically, with different existing automatic algorithms (Simplex, NeadMelder). A manual fitting cannot reach the accuracy of an algorithm, but algorithms often have difficulties in fit convergence with the complex IBA spectra. The authors recommend evaluations and recommendations for the selection of input data and data evaluation procedures.

A definition of standards for data acquisition, analysis, and uncertainties for IBA along these lines opens the perspective for a high degree of similarity of results produced by different labs, boosting the credibility and scientific impact of IBA. For the scientific proof of this success, the authors recommend a round-robin test with samples specific for fusion. The selection of samples should be drawn along the line of expected systematic differences between the labs and probe the potentially weakest points. The technically probable differences are considered to lie in angular accuracy of detectors and samples due to alignment and tolerances, beam energy, and the integration of beam charge/secondary electron correction (Particle*Sr). These differences transfer to differences in measured total elemental content, layer thicknesses, and stoichiometry. The authors therefore suggest a round robin test for the determination of $\mathrm{D}$ retention in $\mathrm{W}$ and bulk and composition analysis of $\mu \mathrm{m}$ thin films.

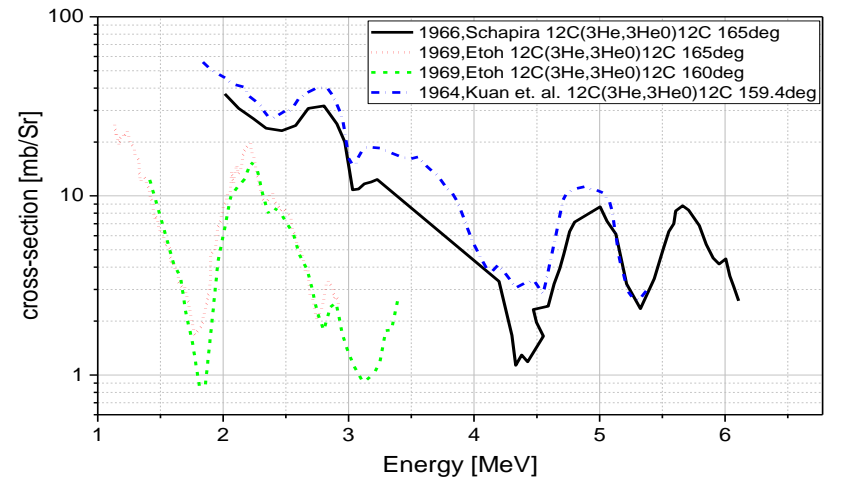

Figure 12. The cross-sections for non-Rutherford elastic scattering of ${ }^{3} \mathrm{He}$ from ${ }^{12} \mathrm{C}$ available in IBANDL exhibit differences over orders of magnitude in spite of similar conditions.

\section{Conclusions}

We have demonstrated the importance of ion-beam analysis for fusion research, connected to the presence of special elements such as Be and isotopes such as $\mathrm{D}, \mathrm{T},{ }^{15} \mathrm{~N}$, and other tracers, and the importance of full compositional analysis including minute quantities for understanding the underlying plasma-surface interactions. In addition, we discussed the challenging requirements for ion-beam analysis in fusion research arising from the broad range of isotopes and elements, required input data, layered sample structures, sample roughness, sample size and mapping, and the handling of hazardous materials.

The high level of international cooperation in fusion research yields advantages by providing a high variety of exposure and analysis setups optimized for different tasks inside the fusion project, but also results in problems of inter- 
comparability and standardisation. The success of the IBA community and its advantage for fusion research strongly rely on the credibility and acceptance of the technique.

Therefore, the authors conclude the following recommendations for future activities with details given in the preceding chapters:

- Provision of facilities for handling of hazardous materials (tritium, activated samples, beryllium) for existing experiments and ITER;

- Standardisation of measurement and evaluation procedures;

- Determination and possibly evaluation of crosssections and stopping powers for elements and isotopes with relevance for fusion;

- International round-robin test with fusion relevant samples for determining the accuracy and comparability of different laboratories.

\section{References}

[1] Federici G et al, 2001 Nucl. Fusion 411967

[2] Hofer W O and Roth J (Eds), Physical Processes of the Interaction of Fusion Plasmas with Solids, Academic Press, New York, 1996.

[3] Philipps V et al, 2002 Vacuum 70399

[4] Roth J et al, 2009 J. Nucl. Mater. 390-391 1

[5] Rubel M et al, 2013 J. Nucl. Mater. 438 S1204

[6] Ström P et al, 2016 Rev. Sci. Instrum. 87103303

[7] Kantre K et al, Nucl. Instrum. Methods Phys. Res. B, submitted

[8] Bykov I et al, 2016 Nucl. Instrum. Methods Phys. Res. B 371 370

[9] Linnarsson M K et al, 2012 Rev. Sci. Instrum. 83095107

[10] Ström P et al, 2017 Nucl. Mater. Energy 12472

[11] Draxler M et al, 2004 Vacuum 7339

[12] Markin S N, PhD thesis, JKU Linz (2008)

[13] Foteinou V et al, 2018 Phys. Rev. C 97035806

[14] Apostolopoulos G et al, 2016 Nucl. Mater. Energy 9465

[15] Vlastou R et al, 2007 J. Radional. Nucl. Chem. 272219

[16] Widdowson A et al, 2014 Phys. Scr. T159 014010

[17] Baron-Wiechec A et al, 2015 J. Nucl. Mater. 463157

[18] Widdowson A et al, 2017 Nucl. Mater. Energy 12499

[19] Widdowson A et al, 2017 Nucl. Fusion 57086045

[20] Catarino N et al, 2017 Phys. Scr. T170 014059

[21] Raepsaet C et al, 2009 Nucl. Instrum. Methods Phys. Res. B 2672245

[22] Bernard E et al, 2013 J. Nucl. Mater. 43, S975

[23] Uglov V V et al, 2015 Nucl. Instrum. Methods Phys. Res. B 354264

[24] Linsmeier Ch et al, 2001 Phys. Scr. T94 28

[25] Möller S et al, 2018 Nucl. Mater. Energy 179

[26] Martynova Y et al, 2017 Nucl. Mater. Energy 12648

[27] Windmüller A et al, 2018 Solid State Ionics 320378

[28] Behrisch R et al, 2000 J. Nucl. Mater. 28142

[29] Peeper K et al, 2013 J. Nucl. Mater. 438 S887

[30] Peeper K et al, 2014 Phys. Scr. T159 014070

[31] Lessmann M T et al, 2017 J. Nucl. Mater. 48634

[32] Fazinić S et al, 2018 Anal. Chem. 905744

[33] Hakola A et al, 2017 Nucl. Fusion 57066015
[34] Brezinsek S et al, 2017 Nucl. Fusion 57 116041-1

[35] Pucella G et al, 2017 Nucl. Fusion 57 102004-1

[36] Caniello R et al, 2017 Nucl. Mater. Energy 109

[37] Wielunska B et al, 2016 Nucl. Instrum. Methods Phys. Res. B 387103

[38] Wielunska B et al, 2019 Nucl. Instrum. Methods Phys. Res. B 440202

[39] Mayer M et al, 2009 Nucl. Instrum. Methods Phys. Res. B 267 506

[40] Langley R A et al, 1974 J. Nucl. Mater. 53257

[41] Schwarz-Selinger T, 2017 Nucl. Mater. Energy 12683

[42] Mayer M et al, 2018 Nucl. Mater. Energy 17146

[43] Farrokhi S et al, Bulletin d'Information Scientifique et Technique du CEA, No. 72 (1972) 65

[44] Kakuee O et al, 2012 Acta Phys. Polonica A 122132

[45] Jokar A et al, 2018 Nucl. Instrum. Methods Phys. Res. B 431 25

[46] Kakuee O et al, 2016 Nucl. Instrum. Methods Phys. Res. B 371156

[47] Mokhles F. et al, 2016 Nucl. Instrum. Methods Phys. Res. B 37380

[48] Nikbakht T et al, 2018 Ultramicroscopy 186112

[49] Vavpetič P et al, 2017 Nucl. Instrum. Methods Phys. Res. B 40469

[50] Kelemen M et al, 2017 Phys. Scr. T170 014067

[51] Kelemen M et al, 2017 Nucl. Instrum. Methods Phys. Res. B 404179

[52] Markelj S et al, 2016 J. Nucl. Mater. 469133

[53] Markelj S et al, 2017 Nucl.Mater. Energy 12169

[54] Založnik A et al, 2016 Nucl. Instrum. Methods Phys. Res. B 371167

[55] Vogel-Mikuš K et al, 2009 Nucl. Instrum. Methods Phys. Res. B 2672884

[56] Martin J A et al, 1988 Appl. Phys. Lett. 522177

[57] Yu N et al, 1995 Nucl. Instrum. Methods Phys. Res. B 99566

[58] Barton J L et al, 2014 Nucl. Instrum. Methods Phys. Res. B 332275

[59] Simmonds M J et al, 2017 J. Nucl. Mater. 49467

[60] Pathak S et al, 2017 Scientific Reports 711918

[61] Cui S et al, 2018 J. Nucl. Mater. 511141

[62] Chen D et al, 2017 Science Advances 3 eaao2710

[63] Qin W J et al, 2018 Acta Materialia, 153147

[64] Ahlgren T et al, 2006 Nucl. Instrum. Methods Phys. Res. B 249436

[65] Palonen V et al, 2016 Nucl. Instrum. Methods Phys. Res. B 38011

[66] Väyrynen K et al, 2019 Chemistry of Materials 315314

[67] Ahlgren T et al, 2019 Nucl. Fusion 59026016

[68] Heikinheimo J et al, 2019 APL Mater. 7021103

[69] www.sandia.gov/research/facilities/technology_deployment_c enters/ion beam lab/accelerators.html

[70] www.psfc.mit.edu/research/topics/accelerators-detectors

[71] Hartwig Z S and Whyte D G, 2010 Rev. Sci. Instrum. 81 $10 \mathrm{E} 106$

[72] Hartwig Z S et al, 2013 Rev. Sci. Instrum. 8423504

[73] Sun C et al, 1989 Nucl. Instrum. Methods Phys. Res. B 40/41 714

[74] Hinks J A et al, 2011 Vac. Sci. Technol. A 29021003

[75] El-Atwani O et al, 2018 Acta Materialia (in press) 
[76] Kirk M A et al, 2018 J. Nucl. Mater. 498199

[77] Li Meimei et al, 2012 Phil Mag. 922048.

[78] Tsitrone E et al, 2009 Nucl. Fusion 49075011

[79] Weckmann A et al, 2018 Nucl. Mater. Energy 1783

[80] Rubel M et al, 2017 Matter. Rad. Extrem. 287

[81] Rubel M et al, 2016 Nucl. Instrum. Methods Phys. Res. B 371 4

[82] Coad J P et al, 2018 Fusion Eng. Des. 13878

[83] Rubel M et al, 2017 Nucl. Fusion 57066027

[84] Rubel M et al, 2013 J. Nucl. Mater. 438 S1204

[85] Krat S. et al, 2017 Nucl. Mater. Energy 12548

[86] Widdowson A et al, 2017 Phys. Scr. T170 014060

[87] Widdowson A et al, 2016 Phys. Scr. T167 014057

[88] Rubel M et al, 1989 J. Nucl. Mater. 161153

[89] Scherzer B M U private communication

[90] Markelj S et al, 2019 Nucl. Fusion 59086050

[91] Rubel M et al., 2007 J. Nucl. Mater. 365-367 877

[92] Wang W et al, 1997 J. Nucl. Mater. 24566

[93] Wielunska B et al, to be published

[94] Mayer M et al, 2001 J. Nucl. Mater. 290-293 381

[95] Frenkel D. and Smit, 2002 Understanding Molecular Simulation: From Algorithms to Applications, Computational Science Series Vol. 1, ISBN-13:978-0122673511, Academic Press

[96] Nordlund K et al, 2018 Nature Communications 91048

[97] Nordlund K 1995 Computational Materials Science 3448

[98] Nordlund K et al, 2016 Phys. Rev. B 94214109

[99] Robinson M and Torrens I, 1974 Phys. Rev. B 95008

[100]Biersack J P et al, 1991 Nucl. Instrum. Methods Phys. Res. B 6177

[101]Eckstein W and Mayer M, 1999 Nucl. Instrum. Methods Phys. Res. B 153337

[102]Ziegler J F, Biersack J P and Ziegler M D, 2008 SRIM - The Stopping and Range of Ions in Matter, ISBN 978-0-96542071-6 SRIM Co., Chester

[103]Mutzke A, Schneider R, and Dohmen R, 2011 SDTrimSP: Version 5.00. IPP, Report, (12/8), http://hdl.handle.net/11858/00-001M-0000-0026-EAF9-A

[104]Hofsäss H et al, 2014 Appl. Surf. Sci. 310134

[105]Arstila K et al, . 2001 Nucl. Instrum. Methods Phys. Res. B 174163

[106]Arstila K et al, 2004 Nucl. Instrum. Methods Phys. Res. B 219-220 1058

[107]Schiettekatte F. 2008 Nucl. Instrum. Methods Phys. Res. B 266 1880

[108]Szilagyi E et al, 1995 Nucl. Instrum. Methods Phys. Res. B 100103

[109]Rauhala E et al, 2006 Nucl. Instrum. Methods Phys. Res. B 244436

[110]Mayer M, SIMNRA Users Guide, Report IPP 9/113, MaxPlanck-Institut für Plasmaphysik, Garching, Germany, 1997. http://hdl.handle.net/11858/00-001M-0000-0027-6157-F

[111]Mayer M, 2014 Nucl. Instrum. Methods Phys. Res. B 332176

[112]Barradas N P et al, 1997 Applied Physics Letters 71291

[113]Doolittle L R, 1985 Nucl. Instrum. Methods Phys. Res. B 9 344

[114]Barradas N P et al, 2007 Nucl. Instrum. Methods Phys. Res. B 262281
[115]Barradas N P et al, 2008 Nucl. Instrum. Methods Phys. Res. B 2661338

[116]Silva T F et al, 2016 Nucl. Instrum. Methods Phys. Res. B 371 86

[117]Schmid K and von Toussaint U, 2012 Nucl. Instrum. Methods Phys. Res. B 28164

[118]Mutzke A. et al, 2011 Nucl. Instrum. Methods Phys. Res. B 269582

[119]Mayer M and Lederer S, 2019 Nucl. Instrum. Methods Phys. Res. B 45367

[120]Mayer M. and Silva T F, 2017 Nucl. Instrum. Methods Phys. Res. B 40675

[121] Mutzke A, Schneider R, Bandelow G, SDTrimSP-2D: Simulation of Particles Bombarding on a Two Dimensional Target-Version 2.0, Report IPP 12/11, Max-Planck-Institut für Plasmaphysik, Garching, Germany, 2013. http://hdl.handle.net/11858/00-001M-0000-0026-E06F-E

[122] Schiettekatte F and Chicoine M, 2016 Nucl. Instrum. Methods Phys. Res. B 371106

[123] Mayer M, 2016 Nucl. Instrum. Methods Phys. Res. B 37190

[124] Mayer M et al, 2016 Nucl. Instrum. Methods Phys. Res. B 38565

[125] Mayer M, 2002 Nucl. Instrum. Methods Phys. Res. B 194177

[126] Woller K B et al, 2013 J. Nucl. Mater. 438 S913

[127] Woller K B et al, 2015 J. Nucl. Mater. 463289

[128] Mayer M et al, 2016 Phys. Scr. T167 014051

[129] Mayer M et al, 2017 Phys. Scr T170 014058

[130] Mayer M et al, 2011 Nucl. Instrum. Methods Phys. Res. B 2693006

[131] Krieger K et al, 2019 Phys. Scr. (in press)

[132] www.srim.org

[133] Wittmaack K, Nucl. Instrum. Methods Phys. Res. B 380 (2016) 57

[134] https://www-nds.iaea.org/stopping/

[135] Behrisch R et al, 1996 J. Nucl. Mater. 233-237 673

[136] Bragg W H and Kleeman R, 1905 Philos. Mag. 10318

[137] Boutard D et al, 1988 Phys. Rev. B 382988

[138] Ziegler J F and Manoyan J M, 1988 Nucl. Instrum. Methods Phys. Res. B 35215

[139] Feng J S-Y et al, 1973 Thin Solid Films 19227

[140] Bohr N, 1948 Matter, Mat. Fys. Medd. Dan. Vid. Selsk. 18.8

[141] Chu W K, 1976 Phys. Rev. 132057

[142] Yang Q et al, 1991 Nucl. Instrum. Methods Phys. Res. B 61 149

[143] Mayer M et al, 2006 Nucl. Instrum. Methods Phys. Res. B 249823

[144] Abriola D. et al, 2011 Nucl. Instrum. Methods Phys. Res. B 2692972

[145] Nocente M et al, 2010 Nucl. Fusion 50055001

[146] Alimov V Kh et al, 2005 Nucl. Instrum. Methods Phys. Res. B 234169

[147] Wielunska B et al, 2005 Nucl. Instrum. Methods Phys. Res. B 37141

[148] Rubel M. et al, 1997 J. Nucl. Mater. 241-243 1026

[149] Rubel M et al, 2005 Vacuum 78255

[150] Merola M et al, 2014 Fusion Eng. Des. 89890

[151] Coad J P et al, 2001 J. Nucl. Mater. 290-293 224

[152] Rubel M et al, 2003 J. Nucl. Mater. 313-316 321

[153] Lagoyannis A et al, 2017 Nucl. Fusion 57076027 
[154] Tsavalas P et al, 2017 Phys. Scr. T170 014049

[157] Tesmer J R et al, 1987 MRS Bulletin 12101

[155] Rubel M, 2006 Phys. Scr. T123 54

[156] Balvanović R et al, 2012 Nucl. Instrum. Methods Phys. Res. A 69017 
The following sections and figures are additional material for the online version only

\section{A.1 Uppsala University, Tandem Laboratory, Uppsala, Sweden}

The Tandem Laboratory at Uppsala University is a national Swedish research infrastructure for ion-beam based materials analysis. It hosts in total four accelerator systems, three of which are relevant for research on fusion reactor materials.

The laboratory hosts a $5 \mathrm{MV}$ 15SDH-2 pelletron accelerator with four ion sources and in total six beam lines. All standard IBA techniques such as RBS, NRA or PIXE are available in multiple end-stations and different techniques can often be performed simultaneously. A nuclear microprobe for $\mu$-PIXE and with annular detector for RBS/NRA is available. The laboratory also features a beam line for irradiation of targets of up to $15 \mathrm{~cm}$ (6 inch) in diameter. Two time-of-flight ERDA (ToF-ERDA) detector systems are available, with one of them based on a segmented gas-ionization chamber allowing for $\Delta \mathrm{E} / \mathrm{E}$ measurements [6]. There is also a beam line for in-situ characterization (RBS, NRA, PIXE) of materials modification by e.g. heating, sputtering or gas exposure [7]. One beam line dedicated to AMS has been also successfully tested for Be-tracer experiments [8].

The second relevant system comprises of a $350 \mathrm{keV}$ Danfysik high-current implanter serving as an ion source. A beamline for implantations of high doses of up to $10^{17}$ particles $/ \mathrm{cm}^{2}$ is available. It is employed for a large variety of primary ion species due to three different types of ion sources. The second beam-line is used for a ToF-MEIS system [9]. This set-up has been recently reconstructed to permit in-situ annealing of targets (see e.g. [10]) and a second detector system providing sub-nm depth resolution. The third beam-line of the system can be used for low-energy RBS, PIXE and NRA.

The third set-up comprises of a ToF-LEIS ultra-high vacuum (UHV) system recently transferred from the University of Linz. Details of the system are available in [11,12]. As key features it provides atomic and molecular beams of $\mathrm{H}, \mathrm{D}, \mathrm{He}$ and $\mathrm{Ne}$ at energies between 0.5 and $10 \mathrm{keV}$. The system is equipped with a broad range of in-situ sample modification and characterization tools such as annealing, sputtering, e-beam deposition and Auger electron spectroscopy (AES).

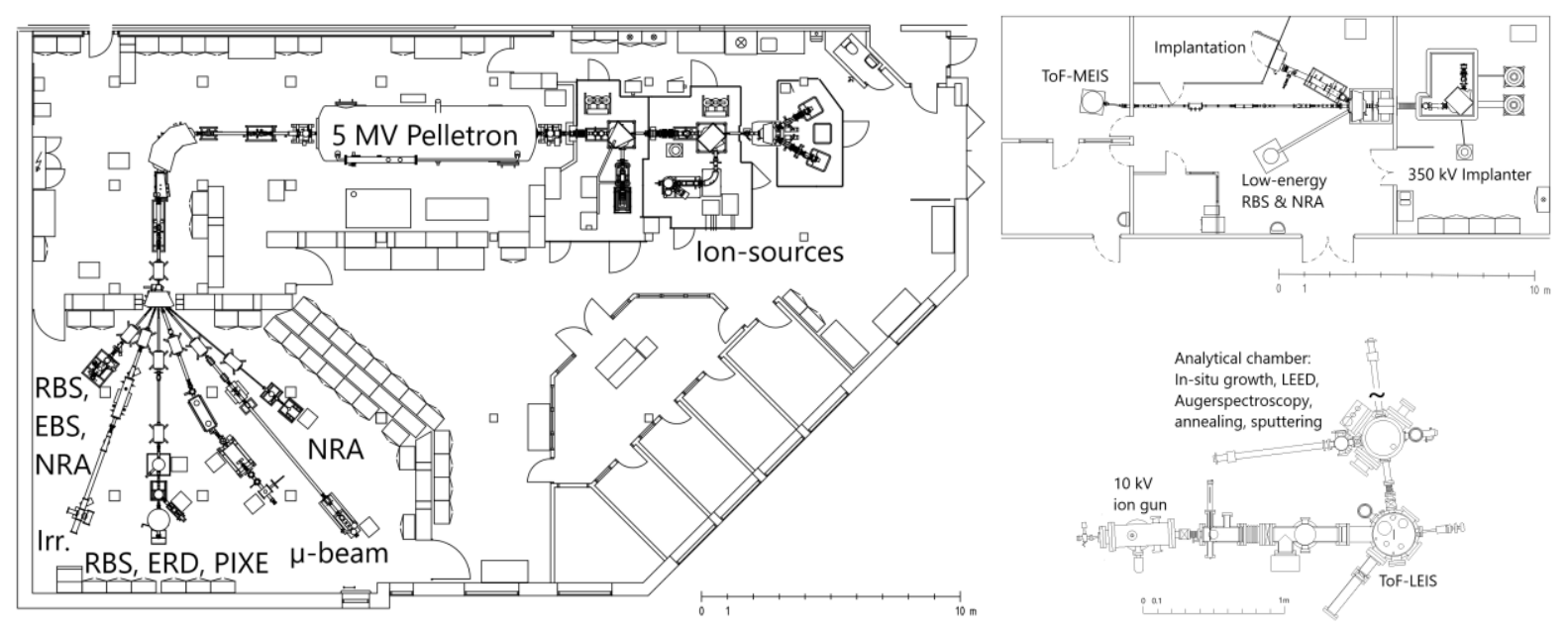

Figure A1. Uppsala University, Tandem Laboratory, Uppsala, Sweden 


\section{A.2 NCSR "Demokritos", Tandem Accelerator Laboratory, Athens, Greece}

The Institute of Nuclear and Particle Physics of NCSR "Demokritos", Athens, Greece, hosts a 5.5 MV van de Graaff Tandem accelerator (HVEC T11/25). It is equipped with a duoplasmatron and a Cs sputter source. A $90^{\circ}$ analysing magnet with $\mathrm{MEZ}^{-1}=145$ is used to select the energy and mass of the accelerated ions, which are then guided to seven different beam lines by means of a switching magnet, also with a $\mathrm{MEZ}^{-1}=145$. Ion-beam analyses are performed using the three basic experimental set-ups presented briefly below.

A universal scattering chamber [13] is installed at the $-25^{\circ}$ beam-leg. It is used mostly for NRA and particle spectroscopy in general. A four-axis computer-controlled goniometer (RBS-50 setup), with a precision of $1 \mu \mathrm{m}$ for translations and $0.01^{\circ}$ for rotations, is installed at the $32.5^{\circ}$ beamline for RBS, EBS, and channelling studies. It is equipped with two surface barrier detectors mounted at $150^{\circ}$ and $170^{\circ}$ inside the chamber. It hosts also a high-performance germanium (HPGe) detector for PIGE measurements. The current of the incident beam is measured with a micro-controlled aluminium chopper blade, which interrupts the beam periodically.

Backscattered ions from a thin gold layer deposited on the blade are detected at a dedicated silicon surface barrier detector.

At the $45^{\circ}$ beam line an Oxford Microbeam set-up is installed. It hosts a $\mathrm{Si}(\mathrm{Li})$ detector for PIXE analysis and a surface barrier detector for NRA. A long-range microscope equipped with a CCD camera is used for the focusing of the beam and for recording the surface of the irradiated sample. A HPGe detector can be placed at $55^{\circ}$ for simultaneous PIGE and PIXE analyses. The system is placed on an artificial granite slab to reduce vibrations. The spatial resolution achieved is $1.2 \times 2 \mu \mathrm{m}^{2}$ for a proton beam of $3 \mathrm{MeV}$.

Apart from the abovementioned set-ups for IBA, a special facility (IR ${ }^{2}$, details in [14]) is dedicated to radiation damage studies, primarily for fusion-relevant materials. Irradiations can be performed at temperatures from $300 \mathrm{~K}$ down to $4 \mathrm{~K}$ by coupling a closed-cycle He refrigerator into the beam line. Furthermore, the electrical resistivity of the irradiated specimen can be measured in-situ enabling real-time monitoring of material damage evolution during irradiation and recovery.

In addition to charged-particle irradiations, neutron irradiations are also performed at the Tandem accelerator. For this purpose the ${ }^{2} \mathrm{H}(\mathrm{d}, \mathrm{n}){ }^{3} \mathrm{He}$ and ${ }^{3} \mathrm{H}(\mathrm{d}, \mathrm{n})^{4} \mathrm{He}$ nuclear reactions are used to produce quasi-monochromatic secondary neutron beams with energies between 4 and $20.5 \mathrm{MeV}$, see [15] for details.

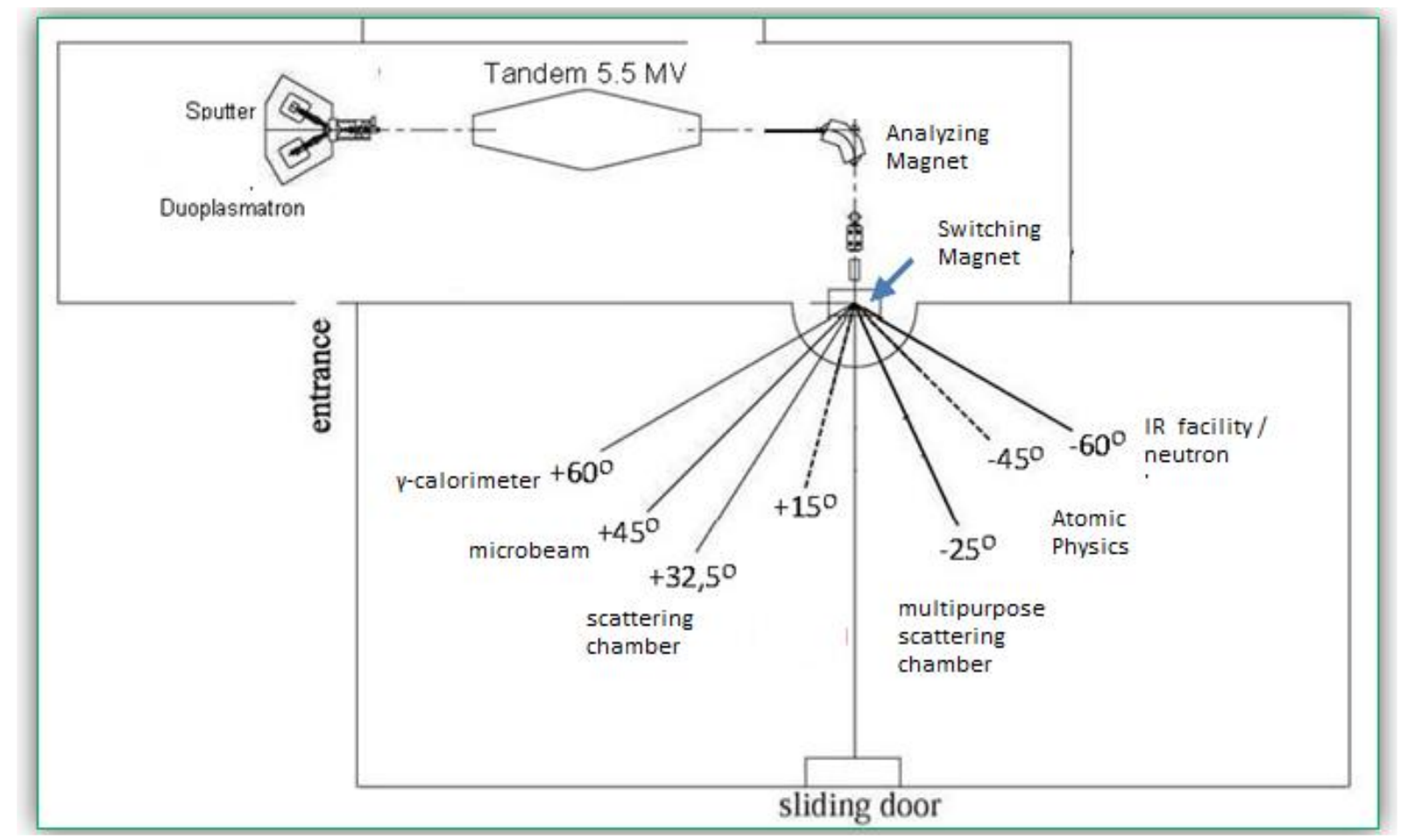

Figure A2. INPP, NCSR "Demokritos", Tandem Accelerator Laboratory, Athens, Greece 


\section{A.3 Instituto Superior Técnico, Universidade de Lisboa, Ion Beam Laboratory, Lisbon, Portugal}

The Laboratory of Accelerators and Radiation Technologies (LATR) is an infrastructure that incorporates two electrostatic accelerators, an ion implanter, an ion microprobe with an external beam, two high resolution X-ray diffractometers and a micro-AMS system. All ion beam techniques are available for characterization and processing of materials. In quantitative elemental analysis the detection limits are the range of ppb without affecting the samples or needs for standards.

Research activites performed in the laboratory are focused on the studies of interaction processes of charged particles with materials with particular emphasis on PFCs from fusion devices. The laboratory has a dedicated chamber to study contaminated materials exposed in tokamaks, mostly from JET with the ITER-like wall configuration. LATR is the unique laboratory in the EUROfusion programme capable of studying full tiles contaminated with tritium and beryllium [16-20]. The analysis station is equipped with an interlock system of glove boxes to handle contaminated materials; more details in Chapter 4. The techniques available for the analysis are RBS, EBS, NRA with ${ }^{3} \mathrm{He}$ beam and PIXE.

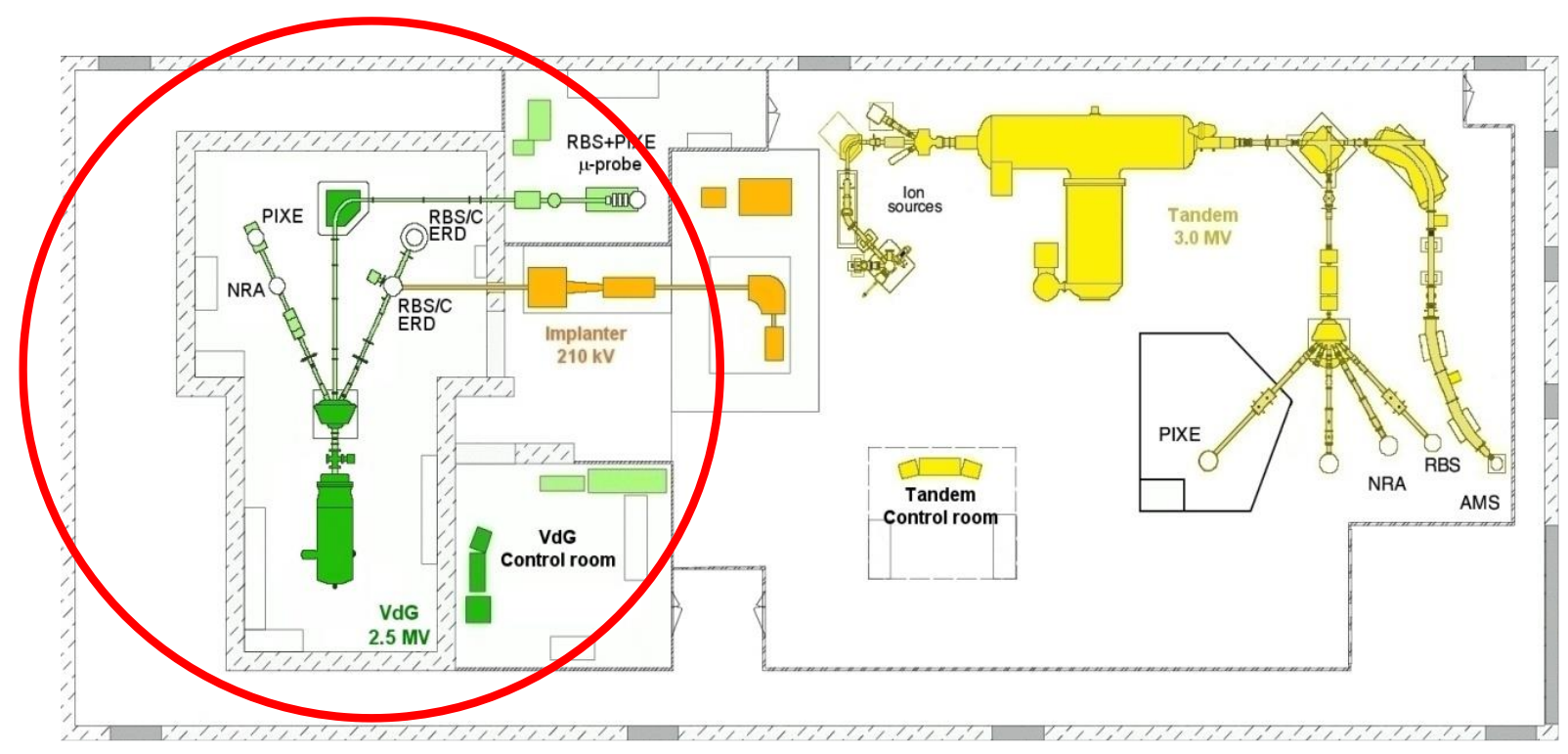

Figure A3. Instituto Superior Técnico, Universidade de Lisboa, Ion Beam Laboratory, Lisbon, Portugal. Encircled facilities are used for studies of fusion reactor materials 


\section{A.4 CEA/Saclay, Laboratory for Light Element Studies (LEEL), France}

The nuclear microprobe of Saclay (France) is constituted of a single ended 3.5 MV van de Graaff generator delivering light element beams $\left(\mathrm{H}^{+},{ }^{2} \mathrm{H}^{+},{ }^{3} \mathrm{He}^{+},{ }^{4} \mathrm{He}^{+}\right)$connected to two beam lines. It allows all standard microbeam analysis techniques (PIXE, RBS, NRA, ERDA). One of the beam lines ends in a shielded chamber devoted to radioactive sample analysis [21]. This chamber is surrounded by thick concrete walls and admits samples with activities up to $100 \mathrm{GBq}$. Particle-charged detectors are meticulously collimated and shielded. A telescope arrangement is frequently employed to discriminate ion beam induced particles from sample radioactivity.

Regarding plasma-wall interaction studies, the standard beam line can be equipped with a low-energy ionsource mimicking slow ion interactions with materials. It has been used for in situ monitoring of deuterium migration and storage in carbon fiber composites previously covering the Tore Supra tokamak walls [22].

\section{IBA chamber for radioactive samples \\ RBS, NRA, ERDA}

IBA chamber equiped with low energy ion source RBS, NRA, PIXE, PIGE, ERDA

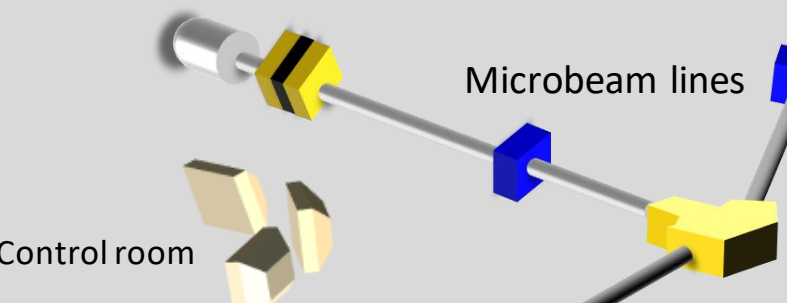

\section{$3.75 \mathrm{MV}$ \\ Van de Graaff \\ ${ }^{1} \mathrm{H}^{+},{ }^{2} \mathrm{H}^{+},{ }^{3} \mathrm{He}^{+},{ }^{4} \mathrm{He}^{+}$}

Figure A4. CEA/Saclay, Laboratory for Light Element Studies (LEEL), France 
A.5 Vinca Institute of Nuclear Sciences, User Facility for Irradiation and Analysis of Materials with Ion Beams, Belgrade, Serbia

The Facility for Modification and Analysis of Material with Ion Beams (FAMA) is a user facility for research and development in materials science with ion beams. FAMA comprises a multiply charged heavy ion source, a light ion source, a proton cyclotron complex and two experimental channels for the modification of materials [23]. The multiply charged heavy ion source is a CAPRICE type electron cyclotron resonance (ECR) ion source operating at the micro-wave frequency of $14.5 \mathrm{GHz}$ with the maximal extraction voltage of $25 \mathrm{kV}$. Concerning the recently growing necessity for the investigation of PFCs from fusion devices, the CERIC-ERIC partner facility FAMA at the Vinca Institute of Nuclear Sciences, offers the following possibilities: irradiation with light positive/negative ions (H, D) up to the energy of $30 \mathrm{keV}$; irradiation with heavy multiply charged positive ions ( $\mathrm{He}, \mathrm{B}, \mathrm{C}, \mathrm{N}, \mathrm{O}, \mathrm{Ne}, \mathrm{Fe}, \mathrm{Xe}$ ) up to the energy of $\sim 500 \mathrm{keV}$ (depending on ion species and degree of ionization). The temperature of the irradiated target can be raised up to $700^{\circ} \mathrm{C}$. The maximal attainable fluences are $\sim 10^{18}$ particles $/ \mathrm{cm}^{2}$. In addition, ion beam-assisted thin film deposition (IBAD) technique for $\mathrm{Si}, \mathrm{Al}, \mathrm{Fe}, \mathrm{Cu}, \mathrm{Cr}$, $\mathrm{Ni}, \mathrm{Pb}, \mathrm{Co}$ and $\mathrm{Ti}$ is also available.

In the near future FAMA will offer the possibility of monocrystalline material modification by channelling implantation of the above listed ion species, with target temperature control in the range from $-100{ }^{\circ} \mathrm{C}$ up to 1000 ${ }^{\circ} \mathrm{C}$.

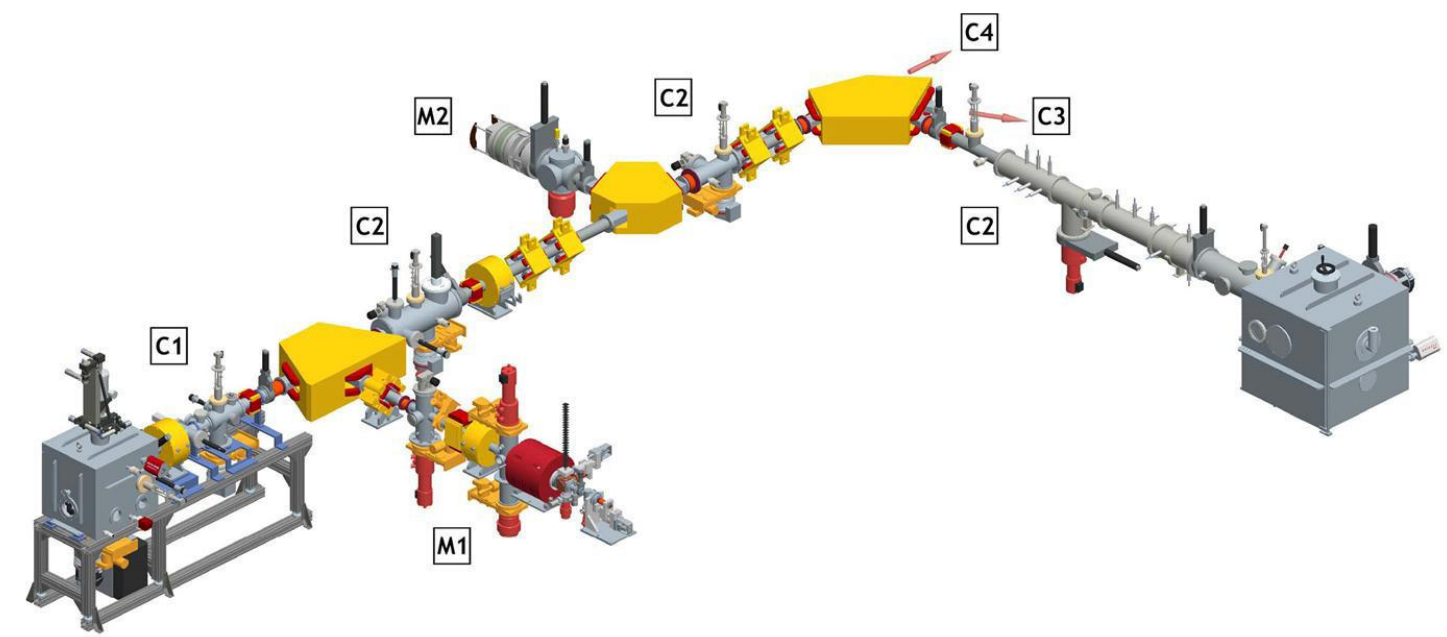

Figure A5. Vinca Institute of Nuclear Sciences, User Facility for Irradiation and Analysis of Materials with Ion Beams, Belgrade, Serbia. Schematic representation of the material modification part of FAMA: M1 - ECR ion source, M2 - multicusp ion source, C1 - channel for monocrystalline material modification, C2 - channel for polycrystalline material modification and thin film deposition [156]. 


\section{A.6 Forschungszentrum Jülich, Tandetron Laboratory, Jülich, Germany}

The 0.1 to $1.7 \mathrm{MV}$ Tandetron accelerator is currently equipped with a lithium charge exchange canal and two duoplasmatron ion sources for negative protons and deuterons $(\leq 30 \mu \mathrm{A})$ or positive ${ }^{3} \mathrm{He}$ and ${ }^{4} \mathrm{He}(\leq 300 \mathrm{nA})$ beams. Three end stations ( $\mu$-NRA, ARTOSS (ART-Of-Surface-Science) [24], Channelling RBS) are installed with one beam line remaining free. The channelling RBS serves the analysis of implanted Si-wafers with sizes up to $300 \mathrm{~mm}$ operated for solid state physics departments. The $\mu$-NRA and ARTOSS end stations focus on analyses of fusion materials (e.g. [25,26]) and, to a lesser extent, lithium ion batteries (e.g. [27]).

The development of the $\mu$-NRA station aimed at producing a working horse with a variable piezo sample manipulator for samples up to $500 \mathrm{~g}$ and $50 \times 50 \times 50 \mathrm{~mm}^{3}$ with simultaneous micro-beam analysis using PIGE, PIXE, NRA, and RBS. The incident beam current is measured by biasing the sample holder against the vacuum chamber. Up to 40 standard $12 \times 10 \times 5 \mathrm{~mm}^{3}$ samples exposed in the linear plasma device PSI-2 can be analysed per day in particular for deuterium retention and surface enrichment of heavy elements.

The ARTOSS device combines several surface analysis and preparation methods in one setup. ARTOSS reaches a vacuum level down to the $10^{-12}$ mbar range in order to delay surface oxidation in particular on beryllium. Besides NRA, ERD, and RBS also a heating stage for 77-1200 K sample temperatures and thermal desorption mass spectrometry (TDS/TPD), X-ray photo-electron spectroscopy (XPS), Low-energy-ion-scattering (LEIS), in-situ sample cleaning and loading by two ion sources with up to $5 / 20 \mathrm{kV}$, an atomic $\mathrm{H}$ source, and a vaporiser for layer deposition are installed. This allows for detailed fundamental studies of materials and hydrogen retention, in particular for nuclear fusion materials. A beryllium laboratory next to the accelerator laboratory allows for preparation and handling contaminated samples for IBA.

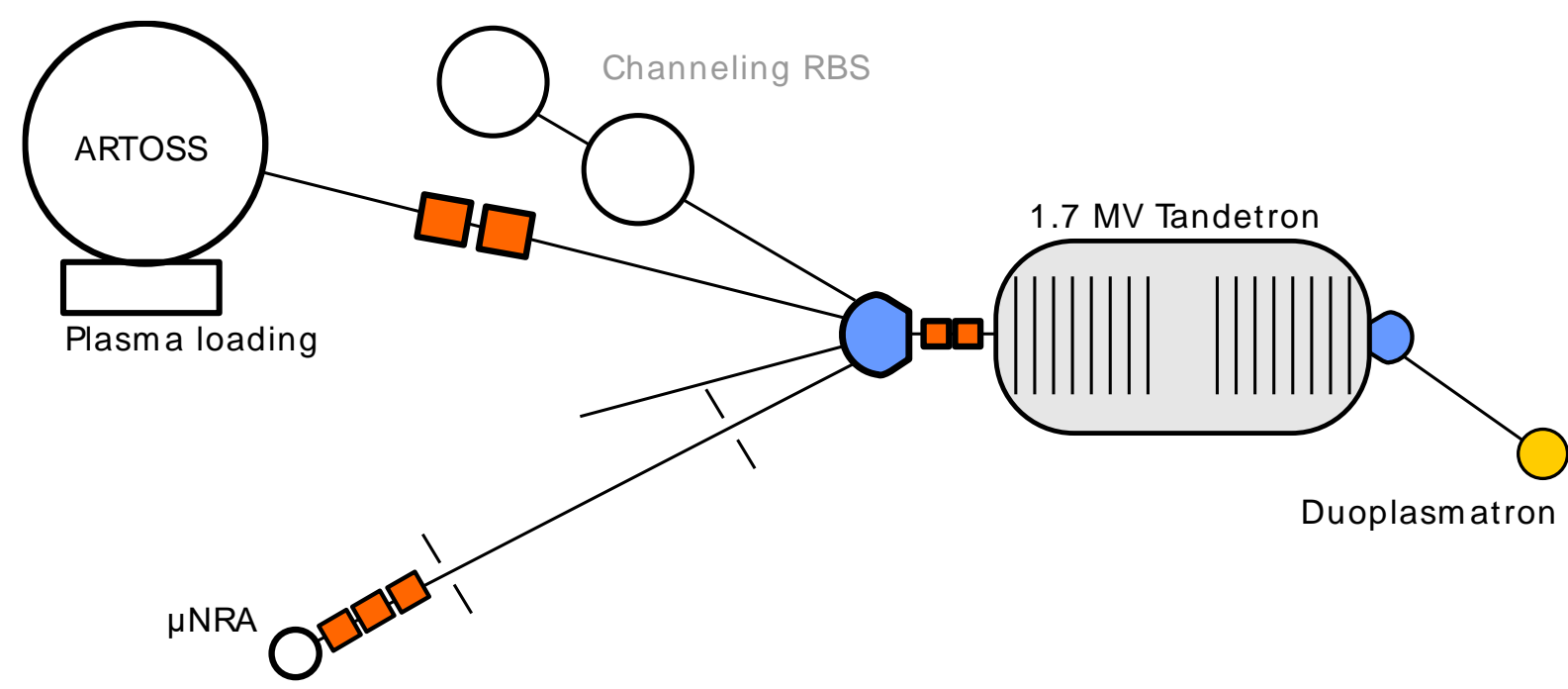

Figure A6. Forschungszentrum Jülich, Tandetron Laboratory, Jülich, Germany. Open squares represent quadrupole magnets, grey filled squares switching magnets, circles measurement end-stations. 


\section{A.7 Maier-Leibnitz-Laboratory (MLL), Garching, Universität der Bundeswehr Munich, Germany}

The Munich 14 MV Tandem accelerator lab (Maier-Leibnitz-Laboratory, MLL) is well known for a highly sensitive accelerator mass spectrometry (AMS) system with a gas filled magnet system (GAMS) as well as for high resolution depth profiling by elastic recoil detection (ERD) using the Q3D-Magnetspectrograph. With the Q3D-Spectrograph a two orders of magnitude lower desorption of $\mathrm{H}$ isotopes is achieved by using $80 \mathrm{MeV}$ incident ${ }^{179} \mathrm{Au}$ ions. The gained sensitivity was demonstrated in a Round Robin analysis of D in a-C:D layers [28]. Sensitivity and separation in particular for light elements has been recently improved by a newly installed TOF-ERD system, in Fe- or C-matrices a sensitivity of approximately $0.1 \mathrm{ppm}$ or $1 \times 10^{13} \mathrm{at} / \mathrm{cm}^{2}$ for H-isotopes is achieved.

Ultimate sensitivity for $\mathrm{H}$ is achieved by a coincidence detection system at the microprobe SNAKE that analyzes for proton-proton scattering events using up to $25 \mathrm{MeV}$ incident protons. It is a unique facility to quantitatively analyze $\mathrm{H}$ distributions in three dimensions with micrometer resolution. The high energy offers the possibility to analyze materials up to a thickness of e.g. $50 \mu \mathrm{m} \mathrm{W}$ or $200 \mu \mathrm{m}$ for C. Sub-ppm sensitivity has been achieved for light materials like diamond, worse sensitivity of few ppm is demonstrated in heavy metals like $\mathrm{Fe}$ or W. Studies of $\mathrm{H}$ retention in irradiated tungsten as well as in steel from fission reactors have been performed to image and quantify the $\mathrm{H}$ distribution in irradiation induced defect structures like cracks and blisters [29]. Future studies are planned to investigate the $\mathrm{H}$ as well as $\mathrm{D}$ retention on grain boundaries in metals.

$\mathrm{D}$ detection with ppm sensitivity is possible by using a deuteron beam and detecting deuteron-deuteron coincidences or through the $(\mathrm{p}, \mathrm{d})$ elastic scattering reaction. This gives the possibility to study adsorption, retention as well as diffusion processes of $\mathrm{D}$ in fusion reactor wall material [30].

Finally, by detecting the elastic scattering signal of the backscattered protons elements heavier than hydrogen can be quantified. The signals from the individual isotopes might be well separated due to the high incident energy. This offers the possibility to clearly identify these signals and map the other elements with spatially correlation to the hydrogen isotopes. This might give further valuable information to the defect analysis for plasma facing wall material. 


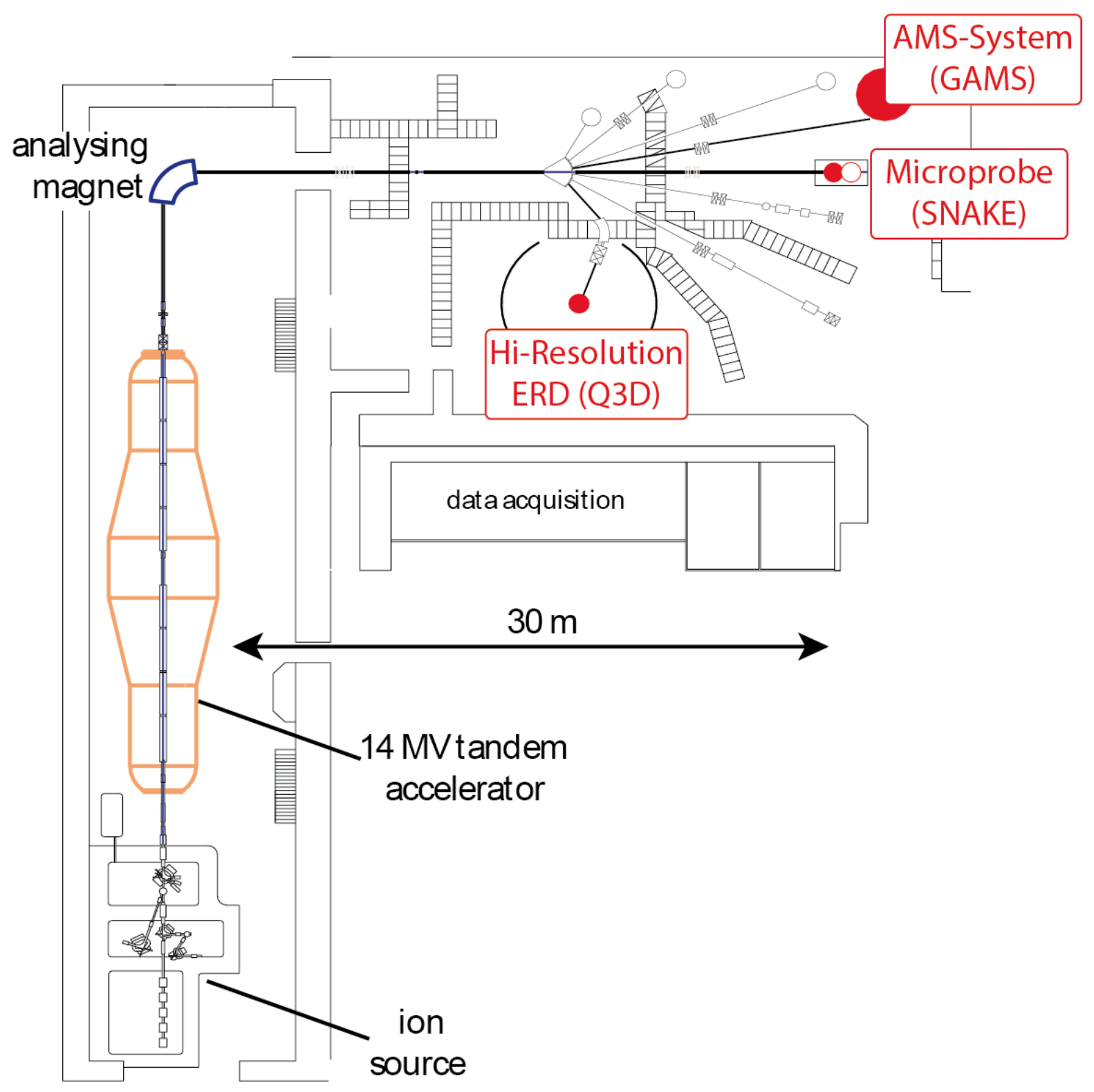

Figure A7. Maier-Leibnitz-Laboratory (MLL), Garching, Universität der Bundeswehr Munich, Germany 


\section{A.8 Ruđer Bošković Institute, Tandem Accelerators Facility, Zagreb, Croatia}

Through the Laboratory for Ion Beam Interactions at the Division of Experimental Physics, the Ruđer Bošković Institute operates and maintains the Tandem Accelerators Facility, that physically consists of the $6 \mathrm{MV}$ Tandem Van de Graaff and 1 MV Tandetron, associated beam lines and nine experimental stations. The accelerators can deliver various ions with energies from $100 \mathrm{keV}$ to tens of $\mathrm{MeV}$. The beam lines in use are equipped with several specialized IBA stations, including general IBA station for RBS, PIXE and PIGE measurements, ToF-ERDA station, capillary MeV ToF-SIMS, a station equipped with goniometer for channelling RBS/PIXE, ion $\mu$-beam station with in-air IBIC, MeV-SIMS and high-resolution PIXE extensions. In addition, two dual beam stations are available, one large for dual beam materials irradiation and the other one equipped with ion $\mu$-beam. A nuclear reaction experimental station is available as well. Recently the facility has been increasingly used to study fusion reactor materials, mainly through international collaborations within the EUROFusion consortium or via bilateral activities including a cooperation agreement with the IAEA [31-36]. So far, four experimental stations have been used for fusion-related studies: general IBA, ToF-ERDA, $\mu$-beam and dual beam irradiation stations. The other three stations could be useful, including a dual station with $\mu$-beam, channelling RBS/PIXE and nuclear reactions station that could potentially be used for measurements of crosssections of importance for fusion research.

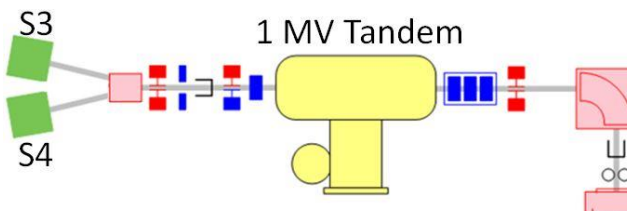

Experimental stations:

E1 - RBS/PIXE/PIGE

E2 - In air

E3 - Dual with $\mu$-beam

E4 - Dual beam irradiation

E5 - TOF-ERDA

E6 - Capillary MeV TOF-SIMS

E7 - Channeling RBS/PIXE

E8 - Nuclear reactions

E9 - Ion $\mu$-beam

In use for fusion energy research

Potential use for fusion research

Figure A8. Ruđer Bošković Institute, Tandem Accelerators Facility, Zagreb, Croatia 
The $3 \mathrm{MV}$ tandem accelerator at IPP Garching is devoted to the analysis of samples from fusion devices and from laboratory experiments for fusion research. It is equipped with a Cs sputter ion source and an RF ion source with $\mathrm{Li}$ vapour charge exchange canal for ${ }^{3} \mathrm{He}$ and ${ }^{4} \mathrm{He}$. Currently three beam lines with five end stations are operational; a fourth beam line is under construction. The RKS station allows analysis of small samples up to $100 \times 20 \times 1 \mathrm{~mm}^{3}$ at incident angles from $0^{\circ}$ to about $80^{\circ}$. A Faraday shield allows accurate charge integration. Analysis methods are RBS at $165^{\circ}$, NRA at $175^{\circ}[37,38] 135^{\circ}$ [39] and $102^{\circ}$ [40] with large solid angles up to

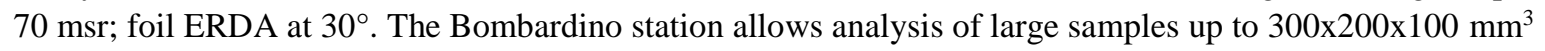
with the weight of up to about $5 \mathrm{~kg}$ using RBS at $165^{\circ}$ and NRA at $150^{\circ}$. The SAK station is equipped with a glove box system, see Fig. 3, for handling samples containing Be and up to $1 \mathrm{GBq}$ of tritium. The Irradiation/Implantation station allows irradiation and radiation damaging of samples up to a diameter of $20 \mathrm{~mm}$ at temperature from room temperature to $1200 \mathrm{~K}$ using a beam scanned in $\mathrm{x}$ - and $\mathrm{y}$-direction [41], accurate charge integration is achieved by using four corner Faraday cups. The ToF-IBA station allows for RBS with high depth resolution using heavy ions [42] at $150^{\circ}$, RBS at $165^{\circ}$ and NRA at $135^{\circ}$. The in-situ IBA station is currently under construction and will allow implantation using two low-energy ion sources and in-situ RBS and NRA at $165^{\circ}$. 


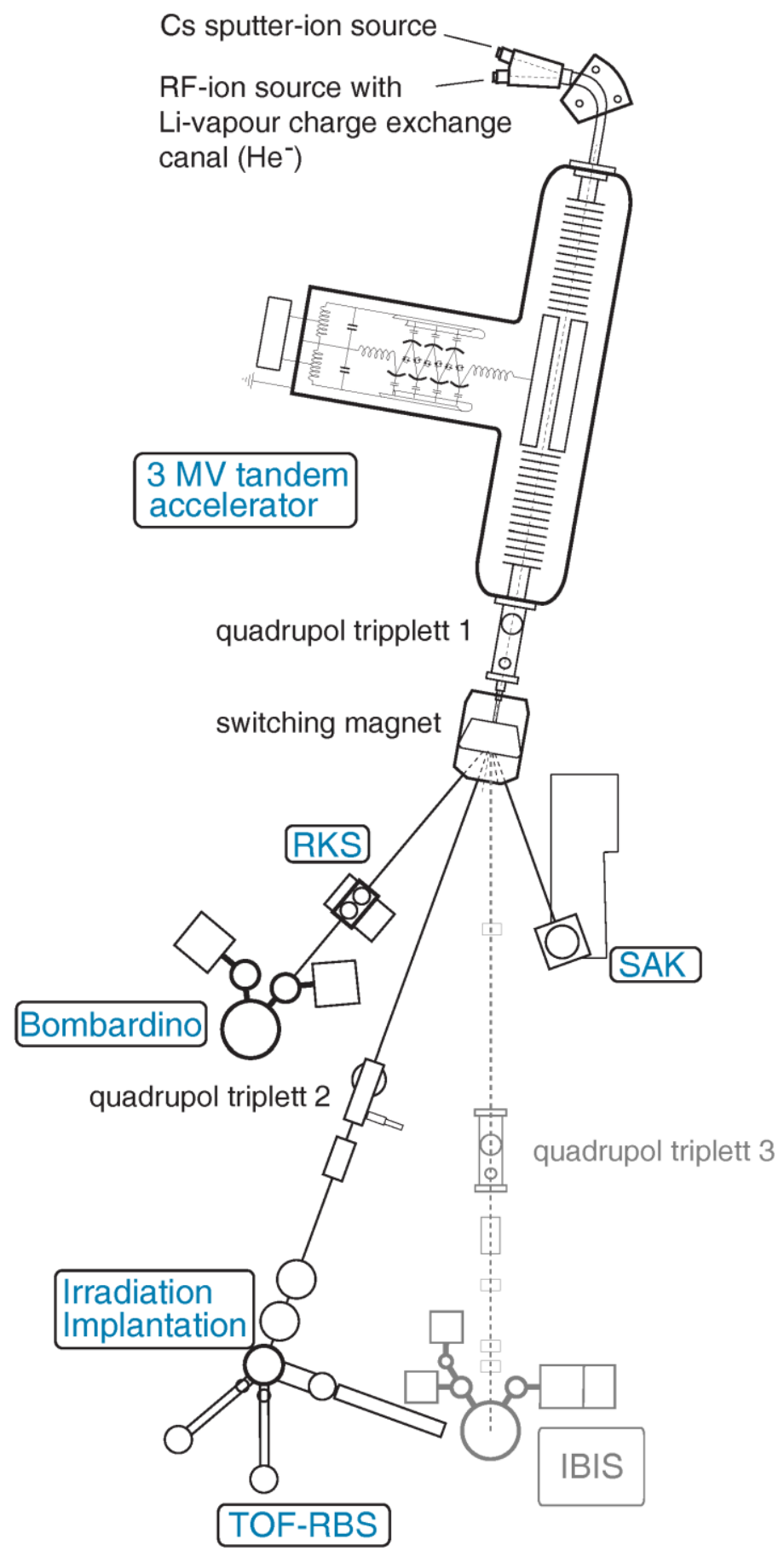

Figure A9. Max-Planck-Institute for Plasma Physics, Tandem Laboratory, Garching, Germany 


\section{A.10 Nuclear Science and Technology Research Institute, Van de Graaff laboratory, Teheran, Iran}

The Van de Graaff Laboratory at the Nuclear Science and Technology Research Institute (NSTRI) equipped with a single-ended $3 \mathrm{MV}$ electrostatic accelerator has experience in applications of energetic ion beams in various fields of science and technology [43]. Atomic and molecular ion beams of protons (up to $10 \mu \mathrm{A}$ ), D, ${ }^{4} \mathrm{He}$ and $\mathrm{N}$ in the energy range of 0.3-3.5 MV are available. Seven beam lines are operational in this lab.

At present, most of the ion beam analysis techniques including PIXE, RBS, channelling RBS, PIGE, NRA, IBIL microscopy for broad beam analysis, as well as nuclear $\mu$-probe with PIXE, RBS, NRA, STIM, IBIL are routinely used for material analysis [44]. Moreover, facilities for ion beam irradiation of material in hot environment are foreseen to study radiation damage by energetic ion beams. Likewise, adequate nuclear instrument modules and detectors for neutron, photon and ion detection are available in this lab.

This lab is actively involved in both basic and applied research activities and has already conducted numerous measurements in nuclear reaction cross-sections, non-Rutherford elastic scatterings and X-ray production crosssections as basic research activities [45]. Moreover, it has developed new instrumentation and methodologies in IBA analysis [46-48]. Analysis systems are applied in various disciplines of archaeometry, environmental science, materials science and nuclear physics as well as materials study in controlled fusion devices.

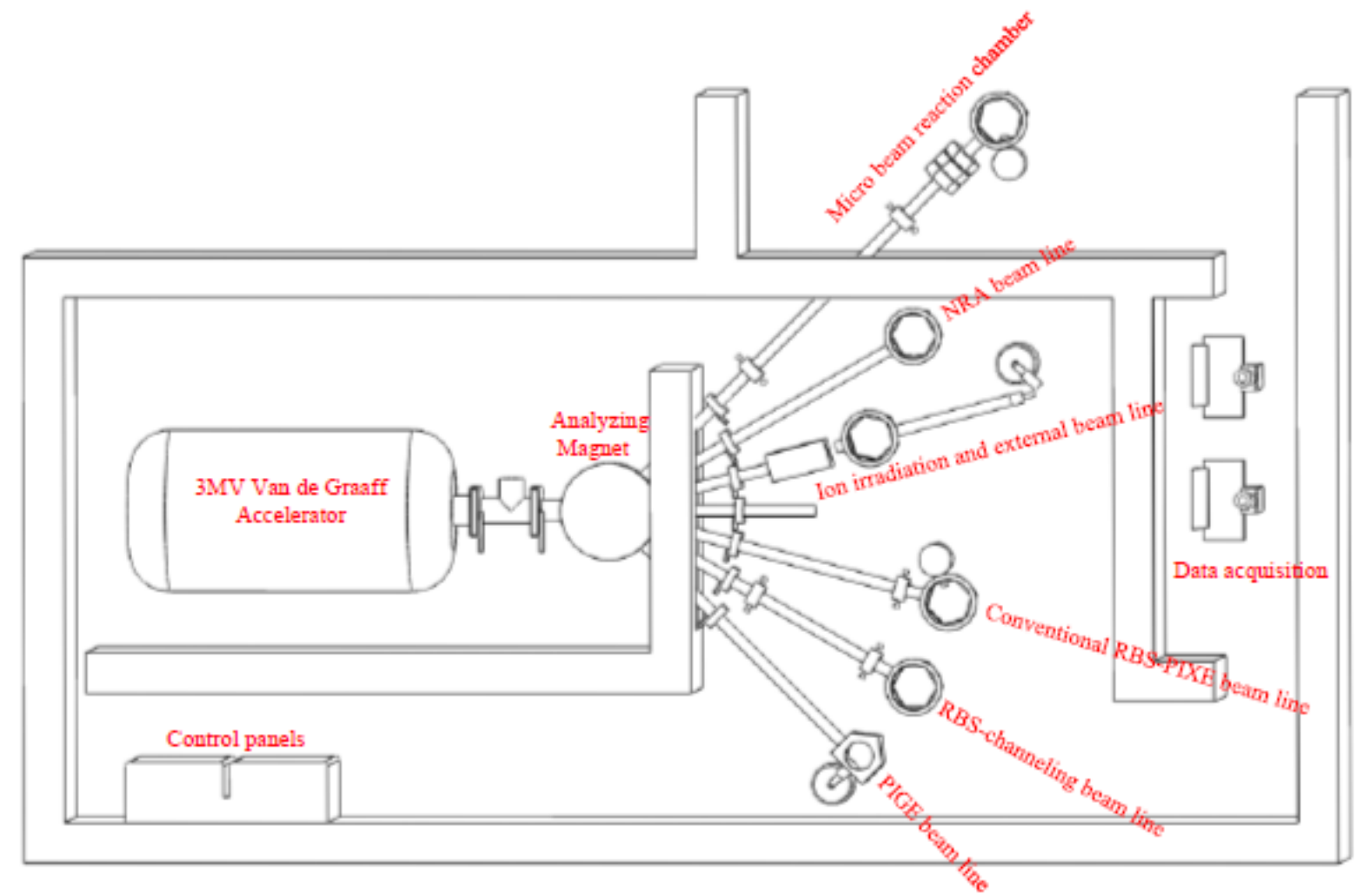

Figure A10. Nuclear Science and Technology Research Institute, Van de Graaff laboratory, Teheran, Iran 


\section{A.11 Jožef Stefan Institute, Microanalytical Centre, Ljubljana, Slovenia}

The Microanalytical Centre at Jožef Stefan Institute, Ljubljana, Slovenia operates the 2 MV High Voltage Engineering Europa Tandem Accelerator with three ion sources: (i) duoplasmatron source coupled with a $\mathrm{Li}$ exchange canal for the production of ${ }^{3} \mathrm{He}$ or ${ }^{4} \mathrm{He}$ ion beams, with the optimised consumption of ${ }^{3} \mathrm{He}$ by using a ${ }^{3} \mathrm{He} /{ }^{4} \mathrm{He}$ gas mixing set-up; (ii) sputter source used for the production of various ions, e.g. lithium and tungsten ion beams used for fusion-related applications; (iii) multi-cups ion source provides high brightness negative hydrogen ions for a proton beam which is typically used for nuclear microprobe [49].

After the acceleration stage the switching magnet is coupled with four beam lines: external beam with focused high energy ion beam possibility, $\mu$-beam line for PIXE, RBS, ERDA, STIM, PIGE, NRA and MeV-SIMS analysis by nuclear microprobe, PIXE/RBS/ERDA (PRE) line and high resolution X-ray spectrometer line. For fusion research the $\mu$-beam line [50,51] and the PRE line are used.

Specifically, in the INSIBA chamber on the PRE line, broad beam analysis can be performed on up to 20 samples mounted on a wheel or in-situ hydrogen isotope (HI) retention studies [52-54] can be performed on a single sample mounted on a heater. The ion beam is shaped by two apertures that can be changed for each irradiation/analysis. They are positioned before the ion beam mesh charge collector, mounted at the entrance to the experimental vacuum chamber. For the detection of deuterium in the sample a $1500 \mu \mathrm{m}$ thick NRA detector is used. Optionally, the sample can be rotated to perform ERDA analysis at glancing angle at $15^{\circ}$ with respect to the probing beam and the ERDA detector is then at $30^{\circ}$ with respect to the probing beam. The sample manipulation is performed with a three-axis goniometer. The INSIBA set-up enables to expose samples to a sub$\mathrm{eV}$ neutral $\mathrm{H}$ or $\mathrm{D}$ atom beam or a $\mathrm{D}, \mathrm{He}$ or $\mathrm{N}$ ion beam (at an energy in the range $300 \mathrm{eV}-5 \mathrm{keV}$ ) and sample temperature control from room temperature to $1000 \mathrm{~K}$ during the ion beam analysis.

On the $\mu$-beam line samples are probed with micrometer lateral resolution, typically used for biological studies [55]. The existing hardware enables beam scanning across an area of $\mathrm{mm}^{2}$ or less for elemental mapping with a resolution up to $256 \times 256$ pixels. For dose normalization a beam chopper combined with an RBS detector is used [55]. The chopper is positioned after the collimating slits and before the scanning coils, cutting a fraction of the ion flux that is then directed onto the sample. In this way, we warrant the proportionality of the backscattering ions from the chopper blades detected by a PIPS detector and the primary ion dose deposited on the sample. Two X-ray detectors are used to detect metallic impurities in the samples in the energy range from $700 \mathrm{eV}$ to $55 \mathrm{keV}$. A RBS detector is positioned at $135^{\circ}$ with respect to the beam direction, covering a solid angle of $5.6 \mathrm{msr}$. For NRA analysis a detector with a solid angle of $0.14 \mathrm{sr}$ is positioned at $135^{\circ}$ with respect to the primary beam direction.

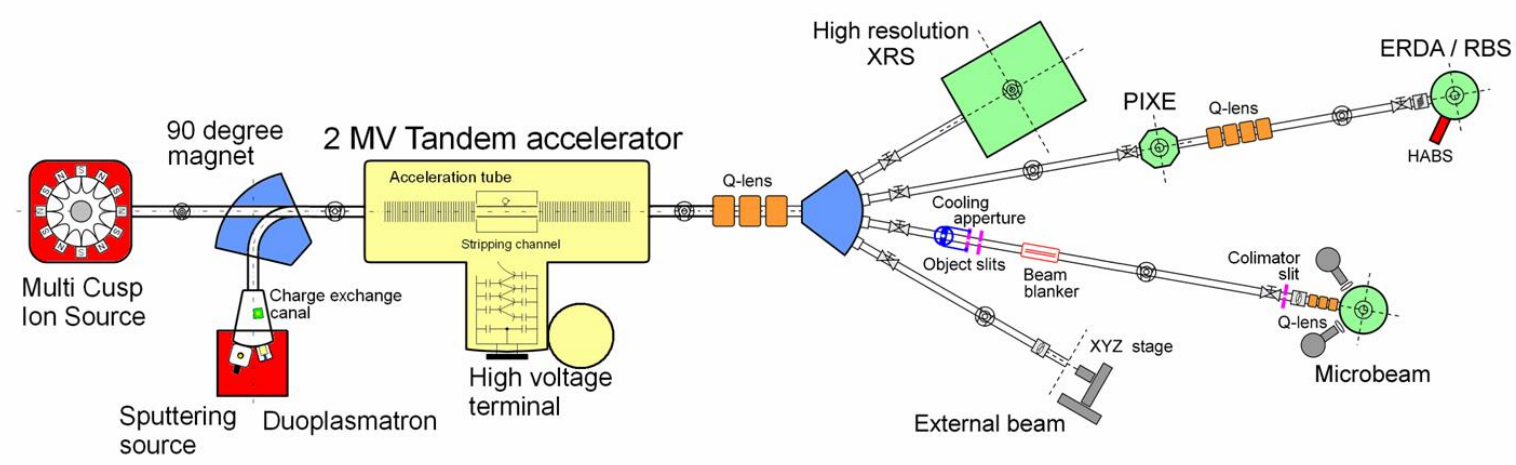

Figure A11. Jožef Stefan Institute, Microanalytical Centre, Ljubljana, Slovenia 


\section{A.12 Los Alamos National Laboratory, Ion Beam Materials Laboratory, New Mexico, USA}

The Ion Beam Materials Laboratory (IBML) established in the year 1986 at the Los Alamos National Laboratory (LANL) was one of the early handful small accelerator facilities in the world dedicated for materials research [56,57]. The IBML, a multiuser research facility, currently hosts a 3 MV NEC Pelletron tandem ion accelerator, a $200 \mathrm{kV}$ Varian DF-3000 production ion implanter and a $200 \mathrm{kV}$ Danfysik high current research implanter. The research programme spans a wide range including material characterization using IBA, material modification and synthesis through ion implantation, and material radiation damage through ion irradiation. The Tandem is able to produce up to $6 \mathrm{MeV}$ protons, $9 \mathrm{MeV}$ alphas, and $15 \mathrm{MeV}$ heavy ions $(\mathrm{C}, \mathrm{Si}, \mathrm{Fe}, \mathrm{Ni}, \mathrm{W}, \mathrm{Au}$ etc.) with sufficient ion beam flux to reach a few to a few tens of displacements per atom (dpa) damage per day in a few microns depth region depending on beam-target combinations. Current beam lines and end stations on the Tandem include the medium energy high temperature irradiation chamber (up to $1270 \mathrm{~K}$ ); alpha radiolysis and helium implantation beam line, and the general-purpose ion beam analysis chamber including RBS, ERDA, NRA, PIXE and Channeling techniques. There is also a joint dual-beam chamber between Tandem and Varian that is used to simulate concurrent neutron displacement damage and gas product $(\mathrm{He}, \mathrm{H})$, existing at a fast fission and fusion environment. A Danfysik high current ion implanter, equipped with a tri-mode ion source (gas-oven-sputter), is able to produce ion beams from majority elements in the periodic table. Depending on the ion species and current requirements, a wide range of beam energies (20-600 keV) and fluences (10 12 to $10^{18}$ ions $/ \mathrm{cm}^{2}$ ) can be implanted over a $5 \mathrm{~cm}^{2}$ area at various temperatures. If needed, wafers of up to $20 \mathrm{~cm}$ (8 inch) in diameter can be implanted with a Danfysik implanter.

Recent fusion plasma facing materials research activities at the IBML include using the $\mathrm{D}\left({ }^{3} \mathrm{He}, \mathrm{p}\right)^{4} \mathrm{He}$ reaction to measure D-retention profiles in D-plasma exposed $\mathrm{W}$ before and after ion irradiation damage [58,59]; investigating ion irradiation damage effects on thermomechanical properties of $\mathrm{W}$ [60,61]; and developing new material nanostructures that can reduce or eliminate "fuzz" nanostructure formation on W surface upon a high flux He irradiation [62,63].

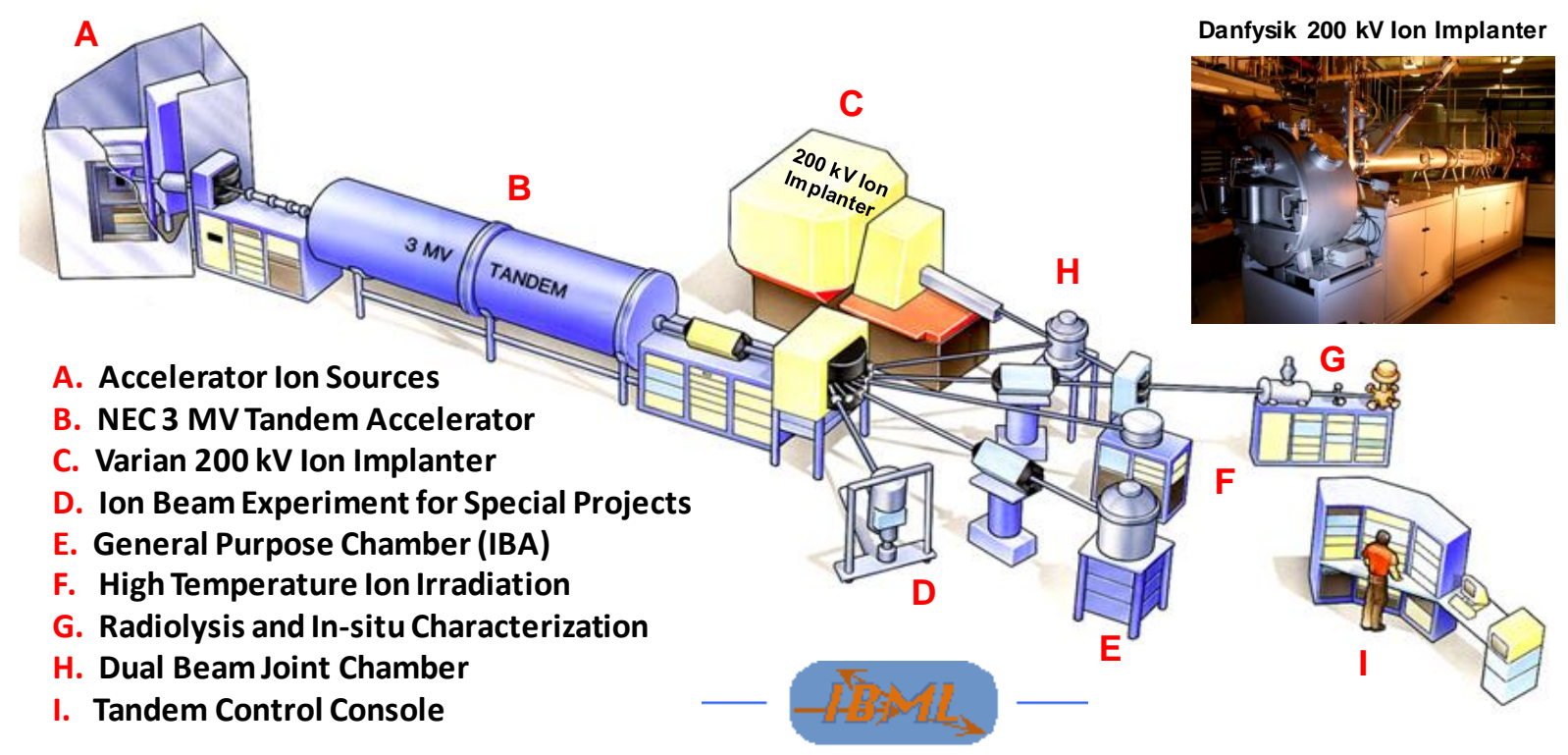

Figure A12. Los Alamos National Laboratory, Ion Beam Materials Laboratory, New Mexico, USA [157] 


\section{A.13 University of Helsinki, Accelerator Laboratory, Helsinki, Finland}

The accelerator laboratory of the University of Helsinki was established in the year 1982. The current research focus is on materials of importance for nanotechnology, micro- and optoelectronics, spintronics and fusion technology [64-68]. Their properties are studied by applying various ion beams, X-ray, ultrasonics and interferometry-based techniques as well as by computational means. The experimental facilities include a $5 \mathrm{MV}$ tandem accelerator, which is mainly used for AMS, ERDA, RBS, in situ irradiation and positron annihilation spectroscopy (PAS) for electrical characterization of materials at variable temperatures. The second accelerator, a $500 \mathrm{kV}$ device, is mainly used for implantation and irradiation of materials, NRA and RBS including channelling. The areas of research with the ion beam analysis are the physical processes taking place in solid matter during and after irradiation by energetic ions. These areas include: interaction and slowing-down of energetic ions in solids, ion irradiation induced effects on the structure of matter, interaction of defects, host atoms, and implanted atoms and diffusion and solubility of impurity atoms.

Further the laboratory has equipment for producing and analyzing nano-materials and layers, which include: cluster deposition, dual e-beam and ion sputter deposition, ion beam dry etching facility for nano-structuring and downsizing. A number of other analysis methods are applied: LEED, AES, LEID and AFM / STM including the UHV variable temperature system.

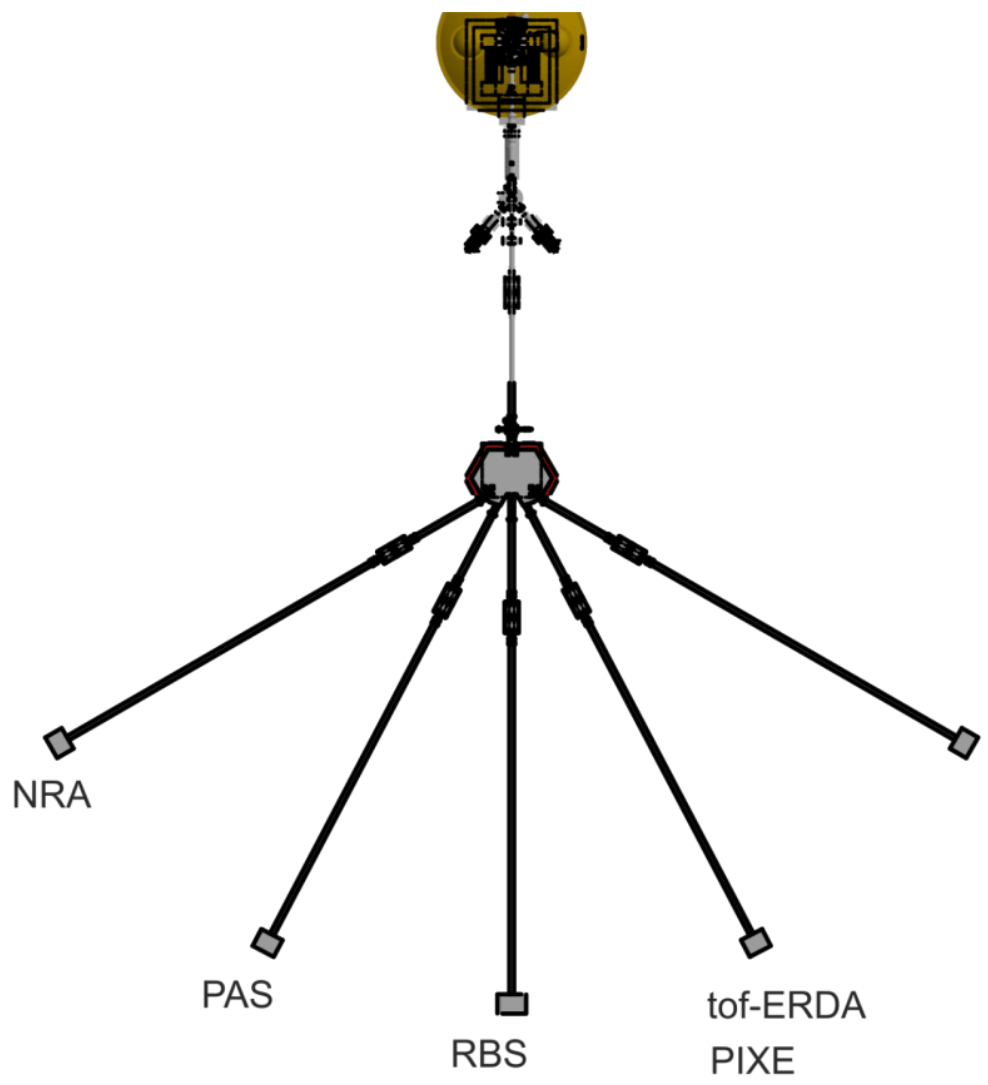

Figure A13. University of Helsinki, Accelerator Laboratory, Helsinki, Finland 


\section{A.14 University of Huddersfield, MIAMI Facility, Huddersfield, United Kingdom}

The Microscopes and Ion Accelerators for Materials Investigation Facility (MIAMI) at the University of Huddersfield comprises two systems (MIAMI-1 and MIAMI-2) that combine transmission electron microscopy (TEM) with ion irradiation, enabling the observation of radiation damage processes at high magnification in real time. The MIAMI-1 system [65] has been in use since 2008 and enables in-situ ion irradiation primarily with gaseous species at energies of up to $100 \mathrm{keV}$. Table A1 provides the technical specification of the MIAMI-2 system.

The main focus of activities, however, is now on the use of the MIAMI-2 system which was funded through a successful bid to the UK Engineering and Physical Sciences Research Council (EPSRC) in 2015 and began operation in 2017. It comprises a $300 \mathrm{kV}$ Hitachi H-9500 TEM that is interfaced with two beam lines; a lowenergy 2-20 kV Colutron system, for implanting $\mathrm{H} / \mathrm{He}$ at fluxes of up to $\sim 300 \mathrm{appm} / \mathrm{s}$; and a medium-energy $350 \mathrm{kV}$ custom NEC system which can provide triply charged ions at up to $1 \mathrm{MeV}$ for most species. This combination of flux, energy and ion species available with this accelerator enables the production of very high damage rates in most materials; for instance up to 0.1 displacements per atom per second (dpa/s) in stainless steel. In contrast, very low fluxes can also be used enabling the effects of single ion impacts to be observed. The ion beams are incident on the specimen at $18.7^{\circ}$ to the electron beam and the two ion beams can be used individually or simultaneously, with both beams mixed and combined into the same trajectory. The irradiations can be performed at all temperatures relevant to fusion materials (heating holder upper limit $\approx 1570 \mathrm{~K}$ ) and also down to cryogenic temperatures $(100 \mathrm{~K})$ which can be particularly useful in determining the importance of the migration of specific defects to radiation damage processes by suppressing their motion.

This dual-beam capability is particularly important for fusion studies as it can be used to replicate the relative rates of displacement damage and helium injection, from transmutation reactions, that will occur in different materials and in different parts of an operational fusion reactor. Finally, the TEM is also equipped with two analytical systems:

(i) An Energy Dispersive X-Ray Spectrometer (EDS) which permits dynamic observation of changes in the distribution of elements within the irradiated material that may result from phenomena such as radiation induced segregation;

(ii) A Gatan Imaging Filter (GIF) which permits Energy Filtered TEM and Electron Energy Loss Spectroscopy (EELS). In addition to information on elemental distribution, this system also permits changes in the configurations of the outer electrons of the atoms present in the irradiated materials to be monitored. This enables changes in bond configurations and thus in, for instance, plasmonic and electronic properties to be followed and mapped in real time.

Table A1. Specification of the MIAMI-2 System

\begin{tabular}{|c|c|}
\hline TEM & Hitachi H-9500 \\
\hline e-Beam Acc. Voltage & $60-300 \mathrm{kV}$ \\
\hline Ion Beam Acc. Voltage & $\begin{array}{l}20-350 \mathrm{kV} \text { (NEC) } \\
1-20 \mathrm{kV} \text { (Colutron) }\end{array}$ \\
\hline Ion Species & Mass 1-200 amu \\
\hline $\begin{array}{l}\text { Angle between } \mathrm{e}^{-} \mathrm{s} \\
\text { ions }\end{array}$ & $\& 18.6^{\circ}$ \\
\hline Environment & $\begin{array}{l}\text { Temp: } \quad 100-1570 \\
\text { injection system }\end{array}$ \\
\hline
\end{tabular}




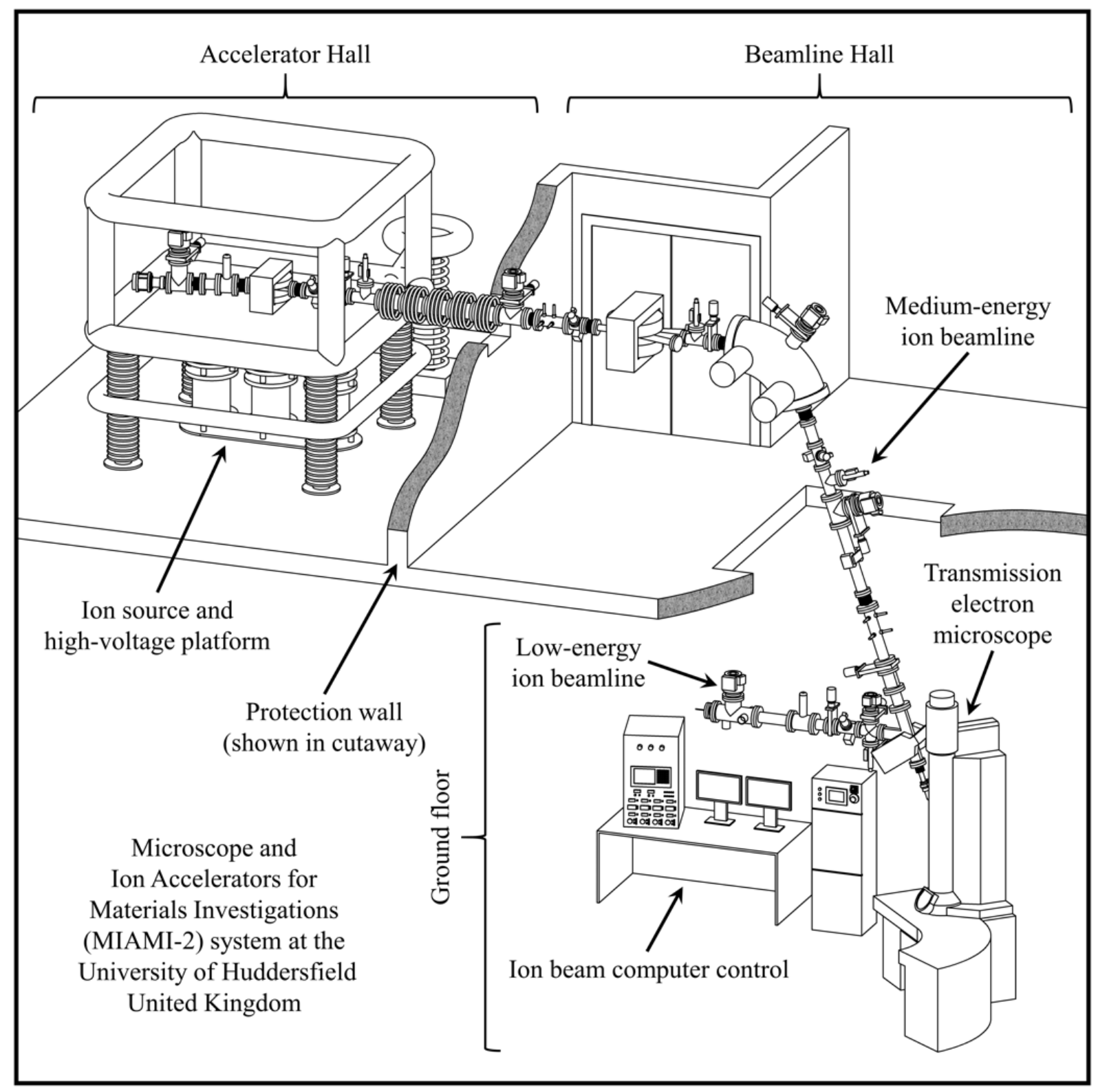

Figure A14. University of Huddersfield, MIAMI Facility, Huddersfield, United Kingdom 


\section{A.15 Argonne National laboratory, IVEM-Tandem Facility, Illinois, USA}

The apparatus at the Argonne National Laboratory is a dual-ion beam for in situ studies of material's microstructure by transmission electron microscopy (TEM). It allows for high-resolution, real time TEM imaging of defect formation and evolution under dual-ion beam implantation and irradiation. A Hitachi 9000 intermediate voltage electron microscope (IVEM) is interfaced to an ion accelerator for irradiation and to a lowenergy ion source for helium implantation, sequentially or simultaneously. The helium beam merges with the accelerator ion beam before entering the microscope with an incident angle of $30^{\circ}$ from the electron optical axis, permitting real time TEM observations under dual-ion beam implantation/irradiation. The microscope operates at voltages up to $300 \mathrm{kV}$ with a point resolution of $0.25 \mathrm{~nm}$. The ion accelerator allows ions with mass from proton to $\mathrm{Au}$ and energy from 40 to $500 \mathrm{keV}$ single-charged and $1 \mathrm{MeV}$ double-charged to be used for irradiation of TEM samples. Ion flux ranges from $10^{10}$ to $10^{12} \mathrm{ions} / \mathrm{cm}^{2} / \mathrm{sec}$, (corresponding to $10^{-5}$ to $10^{-3} \mathrm{dpa} / \mathrm{sec} \mathrm{for} 1 \mathrm{MeV}$ $\mathrm{Kr}$ incident on $\mathrm{Fe}$ ), with a total fluence accuracy of $\pm 10 \%$. The low-energy ion source provides helium ions with energy of $5-20 \mathrm{keV}$ and a flux up to about $2 \times 10^{12} \mathrm{ions} / \mathrm{cm}^{2} / \mathrm{s}$ for in situ helium implantation. A uniform beam of $1.5 \mathrm{~mm}$ in diameter is centered on the position of the electron beam at the sample. TEM sample stages provide in situ environments of heating (300 - $1270 \mathrm{~K})$, cooling $(20-300 \mathrm{~K})$, and straining at low (100-400 K) or high (200$670 \mathrm{~K}$ ) temperatures for in situ studies of materials under combined irradiation, temperature, and stress conditions. Data recording by video and digital camera permit true dynamic experiments to be recorded at the time resolution of $5 \mathrm{~ms}$. The facility has been used extensively for fission and fusion reactor material research [66-68].

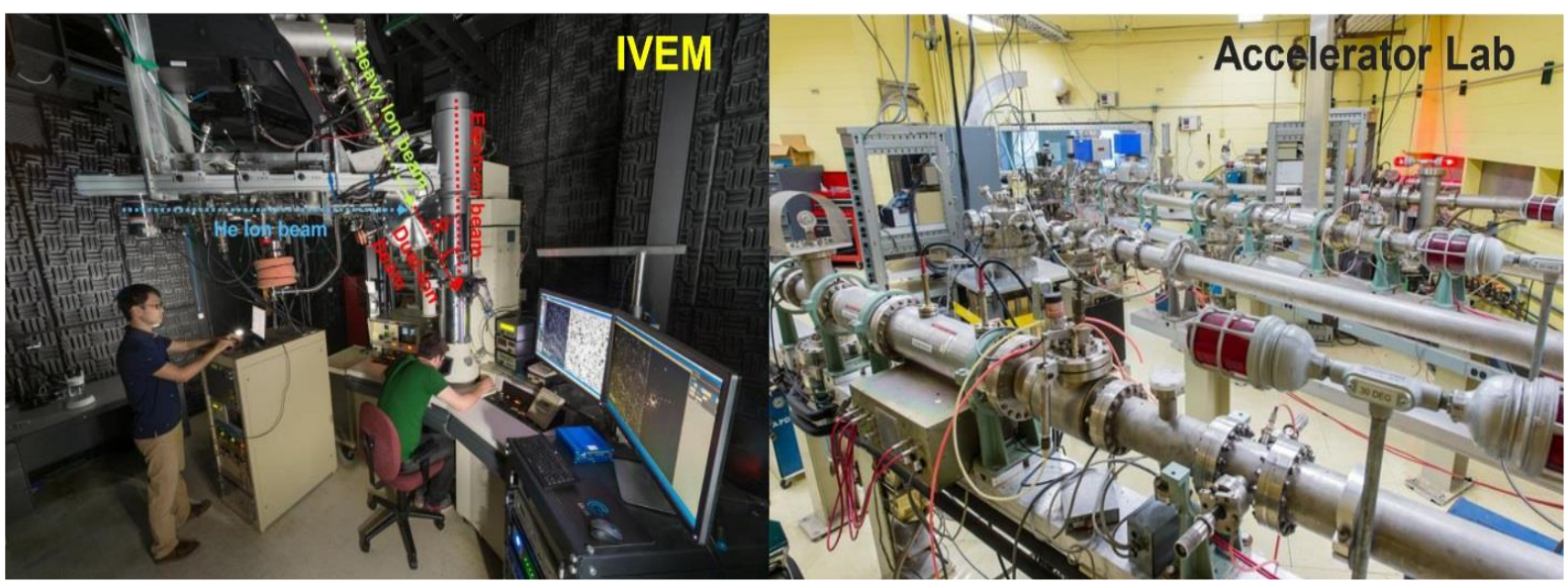

Figure A15. Argonne National laboratory, IVEM-Tandem Facility, Illinois, USA 